\title{
Labor Share Decline and the Capitalization of Intellectual Property Products*
}

\author{
Dongya Koh \\ University of Arkansas
}

Raül Santaeulàlia-Llopis

Washington University in St. Louis

Universitat de València

\author{
Yu Zheng \\ City University of Hong Kong
}

January 2015

\begin{abstract}
We study the behavior of the US labor share over the past 65 years using new data from the post-2013 revision of the national income and product accounts and the fixed assets tables capitalizing intellectual property products (IPP). We find that IPP capital entirely explains the observed decline of the US labor share, which otherwise is secularly constant over the past 65 years for structures and equipment capital. The labor share decline simply reflects the fact that the US economy is undergoing a transition toward a larger IPP sector.
\end{abstract}

Keywords: Labor Share, Intellectual Property Products, 2013-BEA Revision JEL Classification: E01, E20, E22, E25

\footnotetext{
*We thank Michele Boldrin and Ellen McGrattan for their detailed comments. We have also benefited from
} discussions with Martin Peitz. 


\section{Introduction}

The constancy of the labor share (LS), one of the great fantasies of contemporary macroeconomics, is finally gone: The LS declines. Using the most recent national income and product accounts (NIPA) data after the 2013 Bureau Economic Analysis (BEA) comprehensive revision, we find that, the US aggregate LS decreases from 0.68 in 1947 to 0.60 in 2013 (Figure 1). Compared with the LS implied by the pre-revision data (Elsby et al. (2013), Piketty and Zucman (2014) and Karabarbounis and Neiman (2014a)), the decline of the updated LS starts much earlier in (at least) the late 1940s and still continues. These findings shatter the alleged constancy of the LS (Kaldor (1957), Prescott (1986)), which is nothing short of "a bit of a miracle" in Keynes' colorful language.

After carefully analyzing the national income and fixed assets data from the 2013 BEA revision that capitalizes intellectual property products (IPP), we show that the prolonged secular decline of the LS is driven predominantly by IPP capital. In particular, the capitalization of IPP accelerates the measured capital formation and depreciation, barely affecting the time series of relative prices of investment. Removing the effects from IPP capitalization on aggregate capital accumulation, depreciation and the price of investment in a parsimonious framework, we recover a LS that is trendless from 1947 to the present. That is, the shift in the speed at which aggregate capital accumulates and depreciates produced by the increasing importance of IPP capital in the US economy over time drives the observed decline in LS.

While IPP is (and has always been) part of the US economy, it is only after the change in the BEA accounting rules and the expansion of the definition of capital used in national income that the effects of IPP capital on the LS emerge from hideout. On July 31, 2013, the BEA released the 14th comprehensive revision of the NIPA. The major feature of this revision is the capitalization of a larger set of IPP. ${ }^{1}$ That is, the BEA now treats expenditures by business, government and nonprofit institutions serving households (NPISH) for R\&D and expenditures by private enterprises for the creation of entertainment, literary and artistic originals (henceforth, artistic originals) as investments in various forms of durable capital and no longer, as previously done, as expenditures in intermediate non-durable goods (for the private sector) or as final consumption (for the government sector). ${ }^{2}$ These two new forms of investment (R\&D and artistic originals),

\footnotetext{
${ }^{1}$ Other components of the US Economic Accounts, such as the fixed assets tables (FAT) and the industry accounts, are also revised to recognize the newly capitalized IPP. We use the revised data in FAT and the industry accounts in this paper.

${ }^{2}$ This revision also uses an accrual basis to compute the cost of defined benefit pension plans, thereby also accounting for unfunded liabilities. The revision contains a number of other minor improvements: expanding the set of ownership transfer costs for residential fixed assets included as fixed investment and improving the accuracy of the relevant asset values and service lives. It also improves the measurement of financial services offered
} 
combined with software (which has been capitalized as part of equipment since the 1999 BEA revision), form a new class of intangible assets, the so-called IPP. This re-classification of capital implies an upward revision of all previous estimates of private sector GDP and importantly also an upward revision on the consumption of fixed capital to reflect the depreciation of these new assets. Overall, it captures the increasingly important role of IPP in the US economy: The share of IPP in aggregate investment has increased from 8\% in 1947 to $26 \%$ in 2013 (Figure 2); see also McGrattan and Prescott (2014).

Our analysis starts by comparing the old national income data with the new. First, we show that the main difference between pre- and post-revision data lies in the measured depreciation of fixed capital. In the new data, total depreciation has been revised upward by 26.3 percentage points by 2013 , or by an absolute amount ( $\$ 527$ billions) similar to the revision to output. Second, a simple accounting adjustment, where IPP depreciation is removed from the postrevision aggregate depreciation and output, eliminates $55 \%$ of the LS decline in the revised data. Nevertheless, an accounting adjustment, as such, ignores the effects that the capitalization of IPP may have had on other capital income components besides depreciation. Further, software, whose effects on LS we would also like to study, is already present in the pre-revision data.

To consider such effects, we turn to a simple one-sector model as measurement device in which the LS is a function of the net return to capital, the price of investment, the stock of capital and the depreciation rate. We construct from the revised fixed assets tables (FAT) the price of investment, the value of the investment flows, and the depreciation rate of the composite capital good, with and without IPP (i.e., software, R\&D and artistic originals). We then compute two distinct measures of the capital stock, with and without IPP, by using two separate investment equations that differ in the price of investment, the investment flow, and the depreciation rate. Assuming that the net return to capital is the same with and without IPP, we construct a counterfactual LS that, within the context of the model, is net of all effects from IPP capitalization. This yields the main result of our paper.

We find that the increase in the investment in IPP and its capitalization over time explain-for any practical purpose - the entire secular decline in the LS that we document to have started in the late 1940s. The investment in IPP has significantly enhanced capital accumulation, so much so as to more than offset the direct effect of its higher depreciation rate. By 2013 the aggregate capital stock expands by more than $12 \%$, and the capital-output ratio by more than $8 \%$ (Figure 8 ).

by commercial banks by modifying the set of assets and liabilities included in such accounting by introducing borrower defaults and refining the calculation of the reference rate. Finally, it harmonizes the treatment of wages and salaries throughout the accounts and updates to 2009 the reference year for chain-type quantity and price indexes and for chained-dollar estimates. For a detailed discussion, see McCulla et al. (2013). 
Furthermore, the change in the price of investment accounted for by IPP capitalization is minor, and its direct effect on the LS is negligible. While R\&D capital remains the largest contributor to the LS decline, the effects of software are significant and increasing since the early 1980s. These results are robust to the definition of the LS, in particular to restricting the computation of the LS to the corporate sector only. In this case, the LS starts declining only in the early 1980 s, although at a faster rate than the aggregate LS, falling from 0.65 in 1980 to 0.56 in $2013 .{ }^{3}$ Again, for the corporate sector the capitalization of IPP completely explains the decline in the LS.

Our findings hold at the industry level, where we find a strong negative correlation between the LS and IPP capital intensity. The services and information industry-two of the only three industries whose output is expanding relative to the rest of the economy and that account for $35 \%$ of total output in 2013-have experienced a substantial decline in LS and an increase in IPP capital intensity. In addition, the four major industries whose output share declines (i.e., manufacturing of durable and nondurable goods, retail trade and wholesale trade) also display a decline in LS and an increase in IPP capital intensity. In particular, we show that for both durable and nondurable manufacturing, which have experienced the largest declines in LS, the decline is largely due to the increase in IPP investment. That is, manufacturing would not have experienced any decline since the mid-1980s in the absence of IPP capitalization.

In light of our results, it is IPP capital that has generated the acceleration in the capital-output ratio that leads to the decline in the LS over the past 65 years. The observed decline in the LS should therefore be seen as the effect of a transition, a process of structural transformation, toward an economy with a larger IPP sector (see our discussion in Section 5). While it is beyond the scope of this paper to study the growth implications of IPP investment, it seems natural to interpret the higher IPP capital intensity that we are documenting as a source of growth and a sign of prosperity, in contrast to alternative dire assessments associated with labor share decline posed in Piketty (2014).

The rest of the paper is organized as follows. We introduce our definition of LS and discuss its behavior in the post- and pre-revision data in Section 2. In Section 3, we investigate the implications of IPP capitalization on the aggregate LS through its effects on investment, its price, and the depreciation rate, in the context of a one-sector model. Further, we study the separate role of the private and goverment sectors. We study the behavior of the LS and IPP capitalization at the industry level in Section 4. In Section 5, we introduce a two-sector model with two kinds of capital goods, where the declining LS reflects a process of structural transformation toward a larger IPP sector. We conclude in Section 6.

\footnotetext{
${ }^{3}$ These values coincide with the updated data made available online by Karabarbounis and Neiman (2014a).
} 


\section{The US Labor Share: Pre- versus Post-2013 BEA Revision Data}

In this section, we construct the US LS and discuss its behavior. The LS is defined as one minus the ratio of capital income to output. The difference in alternative definitions of LS hinges on the way ambiguous income is treated - that is, income that cannot be unambiguously allocated to capital or labor (mainly, proprietors' income). ${ }^{4}$

\subsection{Benchmark Labor Share}

As our benchmark, we use the standard definition of LS in growth and business cycle modeling from Cooley and Prescott (1995). To deal with the entries of income for which the attribution to either capital or labor is ambiguous, we attribute to capital income the same proportion of the ambiguous income as the proportion of unambiguous capital income to unambiguous income. More precisely, we define ${ }^{5}$

1. Unambiguous Capital Income $(\mathrm{UCl})=$ Rental Income + Corporate Profits + Net Interest + Current Surplus Government Enterprises

2. Unambiguous Income $(\mathrm{UI})=\mathrm{UCl}+$ Depreciation $(\mathrm{DEP})+$ Compensation of Employees $(\mathrm{CE})^{6}$

3. Proportion of Unambiguous Capital Income To Unambiguous Income: $\theta=\frac{\mathrm{UCI}+\mathrm{DEP}}{\mathrm{UI}}$.

4. Ambiguous Income $(\mathrm{Al})=$ Proprietors' Income + Taxes on Production - Subsidies + Business Current Transfers Payments + Statistical Discrepancy

5. Ambiguous Capital Income $(\mathrm{ACl})=\theta \times \mathrm{Al}$.

\footnotetext{
${ }^{4}$ See Gollin (2002) for a comprehensive discussion of this issue, which is well known and needs no further belaboring on our part.

${ }^{5}$ As in Ríos-Rull and Santaeulàlia-Llopis (2010), the definition of LS that we use does not include land, which we regard as inaccurately measured. Further, the flow of funds accounts, the original source for land capital and its rents, no longer publish the series, as also noted by Gomme and Rupert (2007). We can, however, add consumer durable goods to the computation of the LS, under assumptions on the rate of return of the consumption of durables. The results of our exercise do not change with this addition.

${ }^{6}$ While aggregate depreciation shows up as the consumption of fixed capital (CFC) in NIPA, our subsequent analysis is based on the depreciation of fixed assets (DEP) from FAT. We choose to do so, since FAT allow us to disaggregate depreciation by types of capital (i.e., structures, equipment, and IPP), which is important for the subsequent analysis. We have verified that the CFC from NIPA and DEP from FAT are almost identical. Moreover, an additional advantage of FAT data over NIPA is that the FAT provide industry-level series under the North American Industry Classification System (NAICS) throughout the entire sample period, whereas NIPA data split into the Standard Industrial Classification (SIC) and NAICS within the sample period. We return to this point in Section 4.
} 
Then, capital income, $Y_{K}$, is computed as

$$
Y_{K}=\mathrm{UCl}+\mathrm{DEP}+\mathrm{ACl}
$$

which we use to construct our benchmark LS as

$$
\text { Labor Share }=1-\text { Capital Share }=1-\frac{Y_{K}}{Y}
$$

where aggregate output, $Y$, is the gross national product (GNP), that is, the sum of total unambiguous and ambiguous income, i.e., $Y=\mathrm{UCI}+\mathrm{DEP}+\mathrm{CE}+\mathrm{Al} \equiv \mathrm{GNP}$.

\subsection{The Behavior of Labor Share 1947-2013: Pre- and Post-Revision}

Figure 1 shows the time series of the LS constructed from the post-revision data. Clearly, it exhibits a relentless secular decline starting in the late 1940s. The LS begins at 0.678 in 1947 and reaches a historical low at 0.604 in 2013, implying a decline of 11 percentage points over the past 67 years. ${ }^{7}$ Fitting a linear time trend yields a decline from 0.678 to 0.629 during the same period, or a secular decline of 7.2 percentage points.

To visualize the effect of the revision, we plot the benchmark LS constructed from both prerevision and post-revision data for the entire sample in panel (a) of Figure 3. ${ }^{8}$ The pre-revision LS shows a decline over time as well but is not as steep as in the post-revision data. The decline starts at 0.685 in 1947 and ends at 0.637 in 2012, implying a decline of 7 percentage points over the same time period. The magnitude of the decline in the pre-revision LS arguably starts around early 1980s and is similar to that reported by Elsby et al. (2013) under their alternative measures. ${ }^{9}$ In all, in the post-revision data the LS declines $60 \%$ more than that in the pre-revision data. ${ }^{10}$

Since the LS is constructed by combining components of the GNP in the manner specified in Section 2.1, a natural question is "Which components of GNP are affected by the revision?" We investigate each of these components separately. To facilitate our discussion, we group the components of the GNP into three groups: net capital income and depreciation, labor income, and

\footnotetext{
${ }^{7}$ That is, $(0.678-0.604) / 0.678=11 \%$.

${ }^{8}$ We use tables from NIPA and FAT on the BEA's website retrieved shortly before and after the release of the 2013 comprehensive revision. The details of data sources and construction are described in the online Appendix A.

${ }^{9}$ This LS decline since mid-1980s is also discussed in Corrado et al. (2009) that use pre-revision BEA data and implement their own methodology to incorporate a set of IPP components finding a counterfactual LS that remains constant from the early 1950s to the early 1980s and that only declines thereafter.

${ }^{10}$ We postpone our discussion of LS behavior in the corporate sector (as in Karabarbounis and Neiman (2014a)) to Section 3.6.
} 
ambiguous factor income. We plot the differences between the post- and pre-revision measures of each component of GNP in panels (b), (c) and (d) of Figure 3. To assess the magnitude of these differences, we also plot the post-revision to pre-revision difference of GNP in each graph.

Panel (b) of Figure 3 shows that, among components unambiguously attributed to capital income (i.e., $\mathrm{UCl}$ and DEP), depreciation accounts for the lion's share of the differences. In the new data, aggregate depreciation is revised upward every year and by almost as much as the GNP. The revision reaches $\$ 10$ billion by 1959 and grows continuously to over $\$ 531$ billion in 2012, or about $3.2 \%$ of the GNP. ${ }^{11}$ Minor changes are instead made to net interest, rental income, and corporate profits. Net interest is revised upward for 1973-2001 and downward for 2002-2012. The revisions to rental income are small until 2002 (with the largest revision of $\$ 27$ billion downward for 2000). For 2003-2012, the revisions are upward with a peak in 2012 (over $\$ 78$ billion). Corporate profits are revised upward for 1972-1986, downward for 1987-2001, and upward again for 2002-2012. The changes are driven largely by two competing forces: capitalization of IPP, which tends to increase corporate profits, and adoption of accrual-based accounting for defined benefit pensions, which tends to decrease corporate profits. The movements in net interest, rental income, and corporate profit are in opposite directions, so the total effect on $\mathrm{UCl}$ from their revisions (i.e., excluding DEP) is relatively small and never exceeds $\$ 100$ billion.

The total compensation of employees, or the unambiguous labor income, is revised by a small amount relative to the revision to GNP (see panel (c) of Figure 3). The largest upward revision occurs in 2000 (over $\$ 68$ billion), while the largest downward revision is in 1984 (over $\$ 28$ billion). The downward revision for 1972-1988 and the upward revision for 1989-2002 largely reflect the new treatment of defined benefit pension plans. The revision after 2002 is the result of a mixture of statistical revisions to wages, salaries, and pensions ${ }^{12}$ and the introduction of accrual accounting for defined benefit pension plans.

Finally, as to the ambiguous income, the proprietors' income is the only component that shows traces of revision (see panel (d) of Figure 3). For 1985-2011, revisions are downward,

\footnotetext{
${ }^{11}$ The upward revisions to the business CFC exceed $\$ 300$ billion and those to the government CFC exceed $\$ 130$ billion. In both cases, the revisions are primarily due to the capitalization of IPP. For households and institutions, the upward revisions total $\$ 101$ billion for 2012 and are due to the revisions on ownership transfer costs for residential fixed assets as well as the capitalization of IPP. See McCulla et al. (2013), pp.24-25.

${ }^{12}$ These statistical revisions on wages and salaries include "updated measures of misreporting based on data from the IRS [Internal Revenue Service], revised data on wages and salaries paid to and received from the rest of the world from the ITAs [International Transactions Accounts], improved measures of wages paid by Indian tribal governments, revised estimates of wages from cafeteria plans and the incorporation of new and revised data from the Bureau of Labor Statistics (BLS) Quarterly Census of Employment and Wages." The statistical revision to pensions in the later years is due to "the new pensions data from the Department of Labor and new medical expenditures panel survey data from the Department of Health and Human Services." (Quotations are from McCulla et al. (2013), pp.23-24.)
} 
with the largest occurring for 2007 (over $\$ 111$ billion). ${ }^{13}$ For 2012, the proprietors' income is revised upward by almost $\$ 20$ billion, driven largely by the farm proprietors' income after the incorporation of revised source data from the US Department of Agriculture. This downward revision tends to cancel out the upward revision on the $\mathrm{UCl}$, discussed earlier, having little effect on the total of the non-DEP components of the GNP.

The fact that the revision to GNP is driven mostly by the revision to aggregate depreciation suggests a simple counterfactual exercise, feasible thanks to the disaggregated depreciation series from FAT - namely, to remove from the aggregate depreciation series the part of depreciation that comes from the IPP and recompute the LS, a task we turn to next.

\subsection{The Effects of IPP Depreciation on Labor Share}

We have seen in the last section that aggregate depreciation is the component of GNP that has been notably revised. In this section, we remove the part of depreciation derived from the capitalization of IPP to gauge the effect from IPP capitalization on the LS. Before going into details, two clarifications are in order. First, the post-revision aggregate depreciation net of IPP depreciation is not identical to the pre-revision aggregate depreciation. This is because software, a component of IPP, was already capitalized and therefore reflected in the aggregate depreciation in the pre-revision data. Second, as explained in Section 2.2, IPP capitalization does affect components of GNP other than depreciation, even though the effects appear to be largely offsetting. Therefore, such a counterfactual exercise is incomplete in the sense that it ignores the effects of IPP capitalization on other components of GNP. However, it is instructive to let the data speak for themselves to the extent they can. In Section 3, we allow IPP capitalization to affect the LS through the price of investment, the depreciation rate, and capital stock in a one-sector model.

The FAT have disaggregated depreciation data by types of capital. In particular, they have the depreciation of the IPP, which includes software, R\&D, and artistic originals. ${ }^{14}$ We subtract from the post-revision aggregate depreciation the depreciation from IPP recorded in the FAT, while keeping all other components of GNP as they are in the post-revision data. We also revise the GNP downward by the amount of the IPP depreciation. Then we compute the benchmark LS that arises from this accounting exercise. Panel (a) in Figure 4 shows the result in the orange line labeled "Without IPP Depreciation." The magnitude of decline in the LS is greatly reduced.

\footnotetext{
${ }^{13}$ These downward revisions reflect a variety of changes from the capitalization of IPP, the expanded set of ownership transfer costs for residential fixed assets, and the improved measures of the capital gains and losses attributable to corporate partners. See McCulla et al. (2013), p.26.

${ }^{14}$ See Table 2.4 in FAT for private fixed assets and Table 7.3 for government fixed assets.
} 
More specifically, the LS without IPP depreciation declines linearly by 2.1 percentage points from 1947 to 2010. In contrast, the post-revision LS (blue line) shows a linear decline of 6.0 percentage points for that period - a decline almost 3 times as large. This implies that IPP depreciation alone explains $65 \%$ of the LS decline up to 2010 . Including the post-2010 years implies a linear decline of 3.3 percentage points without IPP depreciation versus a decline of 7.3 percentage points with the post-revision data, or a $55 \%$ reduction over the entire sample period. ${ }^{15}$

Further, to put the pre-revision data into perspective, we add the LS constructed by removing depreciation from the non-software components of IPP. The result of this exercise is plotted as the magenta line labeled "Without Non-Software IPP Dep." in panel (b) of Figure 4. This LS, which factors in the effect from the depreciation of only the software component of IPP, behaves in a manner similar to the pre-revision LS. ${ }^{16}$ We find that by removing the non-software IPP depreciation from aggregate depreciation the decline in LS is reduced by about one-half. Precisely, the shift from the post-revision LS (in blue) to the LS excluding non-software IPP depreciation (in magenta) explains $22 \%$ of LS decline. Further removing software depreciation (i.e., entirely excluding IPP depreciation) combines to explain 55\% of the LS decline, as described above.

In panel (c) of Figure 4, we present three different measures of the LS normalized to 1 in 1980: the post-revision measure, the one without IPP depreciation, and the one computed by Piketty and Zucman (2014) and Piketty (2014) for their sample period, 1975-2010. Our major finding is that the LS without IPP depreciation is virtually trendless, while both the post-revision LS and the one constructed by Piketty and Zucman (2014) show large secular declines. Despite the difference in levels, most likely due to the difference in the data sources, the two declining trends (revised NIPA and Piketty and Zucman (2014)) are quite similar. ${ }^{17}$ That is, for the period from 1975 to 2010 chosen by Piketty and Zucman (2014), IPP depreciation entirely explains the US LS decline.

While the goal of this paper is to measure the effects of IPP capitalization on the gross LS

\footnotetext{
${ }^{15}$ In the online appendix, we conduct this counterfactual exercise on each of the components of the GNP and verify that the revision made to depreciation alone explains the change in the behavior of the LS after revision (see panels (a) through (I) of Figure C-1 in the online Appendix).

${ }^{16}$ From 1975 to 2013 , the LS without non-software IPP depreciation declines by 4.85 percentage points, while the pre-revision LS declines by 5.05 percentage points.

${ }^{17}$ Piketty and Zucman (2014) compute an LS that starts at the level of 0.80 in 1974 and decreases to 0.71 in 2010 - that is, a decline of 11.25 percentage points compared with our 11-percentage-point decline reported in Section 2.2. While we use the standard NIPA data published by the BEA, they draw their wealth data largely from the flow of funds accounts published by the Federal Reserve Board. While we include BEA residential capital estimated by perpetual inventory methods, their wealth data include all residential housing at market value. Bonnet et al. (2014) argue that the increase in capital in Piketty and Zucman's accounting is driven mostly by housing capital.
} 
(see next section), in this section, we have pursued the study of the effects of IPP depreciation (i.e., the behavior of the LS net of IPP depreciation) simply as part of the effects of IPP capitalization. Instead, Piketty and Zucman (2014) and Piketty (2014) focus their efforts on explaining the behavior of the net LS (i.e., the LS net of total depreciation from their perspective, not IPP depreciation as we do). ${ }^{18}$ In this context, Krusell and Smith (2014) argue that the choice of working with the net LS, as it ignores depreciation, contradicts standard growth theory by distorting the relationship between growth and savings and limiting the inference that can be made on the effects of (potentially) lesser economic growth on the capital-output ratio. ${ }^{19}$ Here, for completeness, we also construct the net LS and find that total depreciation explains $66 \%$ of the US gross LS decline between 1947 and 2013 - that is, IPP depreciation (by explaining 55\% of the US LS decline) generates most of the effects of total depreciation on the gross LS. This finding is consistent with the results in Bridgman (2014) and Karabarbounis and Neiman (2014b) that suggest that for some countries for which depreciation increases, such as the US, the net LS presents a decline that is less pronounced than its gross counterpart.

\section{The Effects of IPP Capitalization on the Labor Share}

While IPP depreciation alone goes a long way in explaining the LS decline, there are further effects of IPP capitalization that may come through net capital income. To study this, we introduce a simple one-sector model and decompose the total effect of IPP capitalization on the LS into several channels: the price of investment, the depreciation rate, and the investment flows. Our key assumption is that the net return to capital is identical across capital types. We are able to separately identify the effect of IPP capitalization on these variables thanks to the investment, depreciation, and capital stock data by types of capital available from the FAT.

\subsection{Labor Share in a One-Sector Model}

Consider an environment with one sector and one good produced with an aggregate production function, $f$, with two inputs, capital $k_{t}$ and labor $l_{t}$. The national income accounting identity states

$$
c_{t}+i_{t}+g_{t}+n_{t}=y_{t}=f\left(k_{t}, l_{t} ; \Omega_{t}\right),
$$

\footnotetext{
${ }^{18}$ Since Piketty and Zucman (2014) and Piketty (2014) do not recognize the entire set of IPP, removing total depreciation from their perspective is not equivalent to removing total depreciation from ours. In the numbers regarding the net LS we report next, we stick to total depreciation that includes the newly capitalized IPP.

${ }^{19}$ The prediction in Piketty (2014) that LS will continue to decline for many years ahead if growth falls during the 21st century has generated an interesting and heated debate (e.g., Acemoglu and Robinson (2014), Jones (2014), Krusell and Smith (2014) and Rognlie (2014)). See also the discussions in Fernández-Villaverde (2014) and Williamson (2014).
} 
where $c_{t}$ is consumption, $i_{t}$ is investment, $g_{t}$ is government expenditures, and $n_{t}$ are net exports. The production function is assumed to be constant returns to scale (CRS) with an elasticity of substitution different from 1 to allow for LS dynamics. Note that $\Omega_{t}$ captures possibly timevarying parameters. If the production function is constant elasticity of substitution (CES), then only technical progress varies with time. ${ }^{20}$ The investment $i_{t}$, measured in consumption good units, can be converted via a linear technology into a capital good $x_{t}$ usable in production,

$$
x_{t}=v_{t} i_{t}
$$

where the investment-specific technical change (ISTC) - that is, $v_{t}$ - is the inverse of the relative price of investment, $p_{t}=\frac{1}{v_{t}} \cdot{ }^{21}$ Both $i_{t}$ and $v_{t}$ capture changes in the composition of structures, equipment, and IPP investment. The law of motion of capital, in efficiency units $k_{t}^{x}$, is then

$$
k_{t+1}^{x}=x_{t}+\left(1-\delta_{t}\right) k_{t}^{x}
$$

where $\delta_{t}$ is the depreciation rate of $k_{t}^{x}$ for the composite of structures, equipment, and IPP capital. Aggregate capital, $k_{t}^{x}$, therefore, depends on the investment flow, $i_{t}$, its relative price, $\frac{1}{v_{t}}$, and the depreciation rate, $\delta_{t}$. Note that the depreciation rate is allowed to change with time because the composition of aggregate capital also changes, particularly between IPP and non-IPP capital, as we will show.

Let the net return to capital, or the interest rate, be denoted as $r_{t}$ and the gross return to capital, or the marginal product of capital, be denoted as $R_{t}$. The intertemporal investment decision of the firm implies that ${ }^{22}$

$$
R_{t+1} \equiv \frac{\partial f\left(k_{t+1}, l_{t+1}\right)}{\partial k}=\frac{1}{v_{t}}\left(1+r_{t+1}\right)-\frac{1}{v_{t+1}}\left(1-\delta_{t+1}\right)
$$

Under the assumption that the net return to capital is identical across IPP and non-IPP capital goods, the effects of IPP capitalization on the gross return to capital, $R_{t}$, come through $v_{t}$ and

\footnotetext{
${ }^{20}$ For our purpose, a CES production suffices. In the CES production, $\Omega_{t}$ captures constant relative input share parameters, a constant elasticity of substitution, and growing technical progress.

${ }^{21}$ As in Greenwood et al. (1997) and Fisher (2006), we identify ISTC as the inverse of the relative price of investment. Under competitive markets, the relative price of investment in terms of consumption is $\frac{1}{v_{t}}$; that is, the price reflects quality. Under noncompetitive markets, however, the price will reflect both quality and sources of inefficiency such as markups or barriers to technology (or, more generally, investment wedges); see Restuccia and Urrutia (2001), Hsieh and Klenow (2007) and McGrattan and Prescott (2010). Even though here we do not distinguish ISTC from investment wedges, if the effects of IPP capitalization on LS via the relative price of investment are minor, as we find is the case, so will be the effects via ISTC and investment wedges.

${ }^{22}$ Write the Bellman equation of the firm as $V(k)=\max _{k^{\prime}, l} f(k, l)-w l-\frac{k^{\prime}-\left(1-\delta^{\prime}\right) k}{v}+\frac{1}{1+r^{\prime}} V\left(k^{\prime}\right)$. The first order condition (FOC) implies that $\frac{1}{v}=\frac{1}{1+r^{\prime}} V^{\prime}\left(k^{\prime}\right)$. By taking the derivative of the value function with respect to $k$, updating one period, and combining it with the FOC, we obtain (4).
} 
$\delta_{t}$

The effects of IPP capitalization on the LS,

$$
L S_{t}=1-\frac{R_{t} k_{t}^{x}}{y_{t}}
$$

are due to its effects on the following:

1. The price of investment, $\frac{1}{v_{t}}$, that affects the LS indirectly through the accumulation of capital, $k_{t}^{x}$, in (3) and directly through the rate of return, $R_{t}$, in (4).

2. The depreciation rate, $\delta_{t}$, that affects the LS indirectly through the accumulation of capital, $k_{t}^{x}$, in (3), and directly through the rate of return, $R_{t}$, in (4).

3. Investment, $i_{t}$, that affects the LS through its effects on capital accumulation, $k_{t}^{x}$, in (3).

Note that every change in capital income, $R_{t} k_{t}^{x}$, implies an identical change in output, $y_{t}$.

This model allows us to do two things. First, we can measure the full effects of IPP capitalization on the LS through its effects on $v_{t}, \delta_{t}$, and $i_{t}$. Second, we can decompose the effects of IPP capitalization in two different ways: by exploring each of the three determinants $\left(v_{t}\right.$, $\delta_{t}$, and $\left.i_{t}\right)$ in isolation or by exploring $R_{t}$ and the capital-output ratio separately.

\subsection{The Effects of IPP Capitalization on Investment, Its Price, and Depreciation Rate}

In this section, we describe the construction of the three determinants of the LS, $v_{t}, \delta_{t}$. and $i_{t}$, separately with and without IPP capital.

\subsubsection{The Price of Investment}

First, we construct a time series for the price of aggregate capital accounting for the differences in the price of investment in structures, equipment, and IPP.

The construction of the price of investment, $P_{t}^{I}$, closely follows Ríos-Rull et al. (2012). $P_{t}^{I}$ is built as a Törnqvist aggregate of the price index of structures (ST), equipment (EQ), and IPP 
investment with the shares of each type defined $\mathrm{as}^{23}$

$$
s_{t}^{j}=\frac{P_{t}^{I, j} \operatorname{Inv} v_{t}^{j}}{\sum_{j} P_{t}^{I, j} \operatorname{Inv_{t}^{j}}}, \text { where } j=S T, E Q, I P P,
$$

where our measure of aggregate investment includes private and government accounts and both residential and nonresidential investment. ${ }^{24}$ Panel (a) of Figure 5 plots the series $i_{t}$ with and without IPP investment together with their ratio. The series with IPP grows faster than the one without IPP. The two series start at similar levels in the late 1940s but by the end of the sample period, the one with IPP is about $36 \%$ higher than the one without IPP.

To compute the investment price growth let $\lambda\left(x_{t}\right)=\frac{x_{t}}{x_{t-1}}-1$. Then,

$$
\lambda\left(P_{t}^{I}\right)=\left(\frac{s_{t}^{S T}+s_{t-1}^{S T}}{2}\right) \lambda\left(P_{t}^{I, S T}\right)+\left(\frac{s_{t}^{E Q}+s_{t-1}^{E Q}}{2}\right) \lambda\left(P_{t}^{I, E Q}\right)+\left(\frac{s_{t}^{I P P}+s_{t-1}^{I P P}}{2}\right) \lambda\left(P_{t}^{I, I P P}\right) .
$$

The level of the price index for total investment can be recovered recursively,

$$
P_{t}^{I}=P_{t-1}^{I}\left[1+\lambda\left(P_{t}^{I}\right)\right]
$$

with $P_{0}^{I}=1$. Let the price index of consumption be $P_{t}^{C} \cdot{ }^{25}$ The relative price of investment is then defined as

$$
p_{t}=\frac{P_{t}^{I}}{P_{t}^{C}}
$$

whose inverse, $p_{t}=\frac{1}{v_{t}}$, is ISTC.

We compare the price series $p_{t}$ that accounts for the three kinds of capital with the series

${ }^{23}$ The Törnqvist price index specifies, for a variety of components indexed by $j$,

$$
\frac{P_{t}^{I}}{P_{t-1}^{I}}=\Pi_{j}\left(\frac{P_{t}^{I, j}}{P_{t-1}^{I, j}}\right)^{\frac{1}{2}\left[s_{t}^{j}+s_{t-1}^{j}\right]}
$$

where $s_{t}^{j}$ is the share of the value of the variety $j$.

${ }^{24}$ The construction of $I n v_{t}^{j}$ and $P_{t}^{I, j}$ for $j=S T, E Q, I P P A .1 .5$ including a description of the subcategories of investment that structures, equipment and IPP incorporate. We note that, previously, the 1999 BEA revision already incorporated software into equipment capital. Indeed, under such capital taxonomy, Cummins and Violante (2002) correct the series for the price of investment provided by BEA in order to adjust for the quality of capital. Here, instead, we use the post 2013 BEA revision data that separately measures the software prices and the prices of other IPP components; see further details on data sources in the online Appendix A and description of these inputs in online Appendix $B$.

${ }^{25}$ The construction of $P_{t}^{C}$ is discussed in the online Appendix A.1.5. Note that to make the model consistent with the data, we set the price of structures, $P_{t}^{I, S T}$, to be equal to the price of consumption, $P_{t}^{C}$. 
that includes only structures and equipment. They are shown, together with their ratio, in panel (b) of Figure 5. Both series have declined since the 1950s, dropping from an initial level of 1.00 in 1947 to about 0.60 in 2013 . The relative price of investment with IPP is slightly lower than the one without IPP. The ratio between the former and the latter is around 0.995 in the 1960s and between 0.97 and 0.98 since the late 1980s. Altogether, the effect of IPP capitalization on the price of investment seems rather minor compared with the effect of IPP capitalization on aggregate investment.

\subsubsection{Depreciation Rate}

We compute the aggregate capital depreciation rate with IPP as $\delta=s_{K_{S T}} \delta_{S T}+s_{K_{E Q}} \delta_{E Q}+$

$s_{K_{I P P}} \delta_{I P P}$, where $\delta_{j}=\frac{D E P_{K_{j}}}{K_{j}}$ and $s_{K_{j}}=\frac{K_{j}}{\sum_{j} K_{j}}$. The depreciation rate without IPP is computed similarly excluding $\delta_{I P P} .{ }^{26}$ The difference between depreciation rates with and without IPP is shown in panel (c) of Figure 5. The series with IPP is uniformly higher than the series without IPP and visibly accelerates in the 1980s. The series with IPP starts at 4\% in 1947 and ends at $5.2 \%$ in 2013 , compared with an increase from $3.7 \%$ to $3.9 \%$ for the series without IPP.

The depreciation rate in capital structures averages $2.2 \%$ per year during our sample period. The depreciation rate of equipment is around $12 \%$ per year from 1947 to 1982 and rises slightly to $13 \%$ per year by the end of the period. The depreciation rate of IPP is much higher and grows over time. It starts at $15 \%$ per year and grows to $21.4 \%{ }^{27}$ The high depreciation rate of IPP reflects the higher rate at which IPP capital becomes obsolete.

\subsection{Effects of IPP Capitalization on Labor Share through Investment, Its Price, and Capital Depreciation}

In this section, we use our one-sector model to compute the full effects of IPP capitalization on the LS. For a better understanding of these effects, we also provide decomposition exercises through $v_{t}, \delta_{t}$, and capital accumulation.

\footnotetext{
${ }^{26}$ The net capital stock by types of capital is from FAT 1.1 and the depreciation of fixed assets by types of capital is from FAT 1.3. See the online Appendix A.1.3.

${ }^{27}$ See panel (a) of Figure B-1 in the online appendix. Clearly, software is the IPP capital with the largest depreciation rate, starting around 0.30 in the early 1960 s and reaching to an average of 0.34 in the 2000 s. R\&D capital depreciation is roughly around 0.17 since the 1970 s. The lowest depreciation rate is for artistic originals capital with an average around 0.14 since the 1970s; see panel (b) of Figure B-1 in the online appendix. Further, note that while R\&D accounts for around $80 \%$ of total IPP investment in the early 1960 s, this share declines to a steady $50 \%$ in the 2000s; see panel (a) of Figure B-3 in the online appendix. In contrast, the share of software investment in IPP increases from an average of $4 \%$ in the 1960 s to a steady average of $40 \%$ since the 2000 s. Artistic originals account for about $10 \%$ throughout the entire sample. That is, it is the increasing importance of software capital that causes the upward trend in IPP depreciation.
} 


\subsubsection{Total Effects of IPP Capitalization on Labor Share}

To mesaure the full effects of IPP capitalization on the LS we use the definition in (5) and construct a counterfactual LS without IPP capitalization from our one-sector model. First, from the post-revision data, we construct the aggregate investment, the price of investment, and the depreciation rate as detailed in Section 3.2. With this in hand, we use the law of motion of capital in (2) and (3) to build the aggregate capital series, $k_{t}^{x}$. Then, given the LS computed in Section 2.2 using post-revision data, we recover the gross return $R_{t}$ from (5) and the net return $r_{t}$ as the only unknown in (4). The net return to capital $r_{t}$ is set to be the same across all types of capital, an assumption that we maintain throughout. ${ }^{28}$ Second, we construct the IPP-free gross return by combining $v_{t}$ without IPP, $\delta_{t}$ without IPP, and investment without IPP. ${ }^{29}$ Then, we build the aggregate capital stock net of IPP by using the perpetual inventory method as for the one with IPP. The product of IPP-free gross return and capital is our measure of capital income without IPP. Finally, to construct the counterfactual LS without IPP capitalization, we further adjust total output by the absolute change in capital income due to IPP.

Our main result is shown in Figure 6. There we plot LS with IPP capitalization - that is, our benchmark LS from the post-revision data described in Section 2 - and the counterfactual LS without IPP capitalization computed here. In striking contrast to the post-revision LS (blue line), the LS without IPP (orange line) is basically trendless over the past 65 years; the respective linear trends plotted in Figure 6 are for the 1947-2010 period. If we fit a linear trend to the LS without IPP from 1947 to any endpoint between 2008 and 2012, the estimated trend is statistically insignificant. ${ }^{30}$ By adding the value for 2013, the year in which LS reaches its minimum, the estimated slope becomes -0.0018 with a standard error of 0.00084 in 10-year averages. This linear trend has an estimated value of 0.685 in 1947 and 0.673 in 2013, for an absolute decline of 1.2 percentage points of GNP over a period of 66 years; that is one-fourth of the 5.0-percentage-point decline computed with IPP capitalization. ${ }^{31,32}$

\footnotetext{
${ }^{28}$ Given that $k_{t}^{x}, v_{t}$, and $\delta_{t}$ are constructed with post-revision data and with IPP, then the computed LS from equation (5) must be, by construction, identical to the post-revision LS in Section 2.2.

${ }^{29}$ We use the same initial value for both aggregate composites of capital with and without IPP.

${ }^{30}$ Precisely, a linear trend from 1947 to 2008 , at the onset of the Great Recession, yields a nonsignificant slope of -0.000401; a linear trend from 1947 to 2012 yields a negative but nonsignificant slope of -0.001454 .

${ }^{31}$ Although we acknowledge that it is perhaps too soon to decide whether this dip in the LS without IPP from 2009 to 2013 is only temporary, past evidence suggests this is probably the case. For example, we do notice the surging episodes in the LS without IPP starting in 1965 and 1984 or the episodes of LS decline starting in 1971, 1993 and 2006, all of which were of a bigger magnitude than the current dip and reverted to the trend.

${ }^{32}$ We further note that large and persistent cyclical fluctuations of LS, however, survive our scrutiny of IPP capitalization and call for a theory. That is, simple visual inspection of Figure 6 suggests that IPP capitalization does not change the cyclical properties of the LS. Hence, while IPP capitalization can explain the secular decline of LS, the cyclical behavior of LS does not seem much altered by it and remains unexplained.
} 
The moral of this analysis is straightforward: The secular decline in the LS that started in the late 1940 s can be entirely explained by IPP capital. ${ }^{33}$

\subsubsection{A Decomposition of Total Effects}

We describe several decomposition exercises in Figure 7. The first links the one-sector model to the simple accounting exercise of Section 2.3, where we removed the IPP depreciation. Note that from (4), we can express the capital income $R_{t} k_{t}^{x}$ as

$$
R_{t} k_{t}^{x}=\left(\frac{1+r_{t}}{v_{t-1}}-\frac{1}{v_{t}}\right) k_{t}^{x}+\frac{1}{v_{t}} \delta_{t} k_{t}^{x}=\left(\frac{1+r_{t}}{v_{t-1}}-\frac{1}{v_{t}}\right) k_{t}^{x}+D E P .
$$

We use the post-revision data to compute $\frac{1}{v_{t}} \delta_{t} k_{t}^{x}$ without IPP. The LS constructed from such data is shown as the green line in panel (a) of Figure 7. This is the model analogy of removing the depreciation of IPP from the raw data (see panel (a) of Figure 4).

In the second experiment, we begin with the trendless LS without IPP and cumulatively add back the effects of IPP on the price of investment, the depreciation rate and the investment flow (panel (b) of Figure 7). In the construction of the IPP-free LS, if we replace the price of investment without IPP with the price of investment with IPP, the resulting LS largely overlaps with the IPP-free LS (see the purple line label "+ Inv. Price with IPP"). This suggests that the changes in the price of investment induced by the capitalization of IPP play a minor role in the phenomenon we are studying. If we further replace the depreciation rate without IPP by the depreciation rate with IPP, we obtain the green line labeled "+ Dep. Rate with IPP." The effect of IPP capitalization through the depreciation rate is also quite limited. Finally, we replace the investment series without IPP by the aggregate investment with IPP. This brings us back to the LS with the full impact of IPP as computed from the post-revision data. That is, it is the increase in aggregate investment due to the incorporation of IPP that generates the LS decline. ${ }^{34}$

\footnotetext{
${ }^{33}$ We looked further back in history and explored the LS behavior from 1929 to 2013 . We redo the exercises in Sections 2.3 and 3.3 with this extended sample. We obtain results very similar to those reported here for the postwar sample. The LS in the post-revision data trends down with a slope of -0.0049 from 1929 to 2013, while removing the IPP depreciation alone predicts a trend with an insignificant slope of -0.0010 . Removing the effect from IPP capitalization results in a trendless LS series from 1929 to 2013. The figures for these results are in the online Appendix D.

${ }^{34}$ While the role of the price of investment has been emphasized in Karabarbounis and Neiman (2014a) as important in explaining the cross-country differences in the decline of the LS, our result suggests a relatively minor role for the changes in the price of investment due to IPP capitalization in the US. The main difference of our work with respect to that of Karabarbounis and Neiman (2014a) is that we focus on the effects of IPP capitalization. However, we must note that our decomposition follows an accounting framework that does not endogenize the investment response to changes in prices and/or depreciation rates due to IPP capitalization. In that sense, our accounting results might pose a lower bound to the effects of prices as well as depreciation rates. That is, if part of the increase in aggregate investment due to IPP is generated by the decline in the aggregate
} 
In the theoretical derivation of Section 3.1, we identify a direct and indirect channel through which the price of investment and the depreciation rate incorporating IPP can affect the LS (panel (c) and (d) of Figure 7. Panel (c) of Figure 7 shows that the price of investment incorporating IPP has almost no effect on the LS, either directly, through the gross rate of return or, indirectly, through capital accumulation. Surprisingly, panel (d) of Figure 7 shows a small effect of the depreciation rate with IPP on the LS as well. This result masks two competing effects: (i) A higher depreciation rate increases the gross rate of return, $R_{t}$, which tends to increase capital income for a given capital stock, hence reducing the LS (see the purple line labeled "+ Dep. Rate with IPP (Through R)"). (ii) A higher depreciation rate also reduces the accumulation of capital, which decreases capital income for a given rate of return, thereby increasing the LS (see the green line labeled "+Dep. Rate with IPP (Through Cap. Accum.)"). The two effects turn out to be offsetting, leaving the LS only slightly increased, if changed at all, from the reference level.

We have shown that, overall, the increased rate of capital accumulation due to IPP investment is the dominating force behind the LS decline, while the increased rate of depreciation or the reduced price of investment plays lesser roles. ${ }^{35}$ To highlight the contribution of IPP to aggregate capital accumulation, Figure 8 plots three ratios: the capital stock with IPP to the one without IPP, ${ }^{36}$ the output with IPP to the one without IPP, and the capital-output ratio with IPP to the one without IPP, normalizing all ratios to 1 in 1947. Between 1947 and 2013, IPP capital raises the aggregate capital stock by $12 \%$ and the capital-output ratio by $8 \%$ by 2013 , which explains the LS decline - that is, IPP capitalization implies an increased aggregate capital that is roughly three times larger than the implied increase in output. That is, the LS decline simply reflects the fact that the US is growing toward a larger IPP economy and the revised data take this into account. We discuss this assessment further in Section 5.

\subsection{The Role of Software, R\&D, and Artistic Originals Capitalization on Labor Share}

Here, we further examine the components of IPP in the BEA accounts: software, R\&D, and artistic originals. The investment share in IPP associated with R\&D has decreased from $84 \%$ in the early 1960s to around $50 \%$ in the late 1990s, while the investment share associated with software started to increase from null in the early 1960 s to $40 \%$ in the late 1990 s (see panel (a)

investment price brought by IPP, then this could increase the total effects of prices in this decomposition. The same story can be applied to depreciation rates. However, note that our total effects of IPP capitalization on the LS are independent of such endogenization.

${ }^{35}$ As the effects of IPP capitalization on the gross rate of return, $R_{t}$, work through the the depreciation rate and the the price of investment, we find that IPP does not change $R_{t}$ in a significant manner - precisely, only a $2 \%$ increase from 1947 to 2013.

36 This capital series are divided by $v_{t}$ so that captial and output are in the same consumption good units. 
of Figure 9). Interestingly, since the late 1990s the shares of R\&D and software have remained steady throughout the 2000s. The remaining $10 \%$ of IPP investment is attributed to artistic originals.

The contribution of the capitalization of each of these three categories to the LS decline is illustrated in panel (b) of Figure 9. ${ }^{37}$ Starting from the LS without IPP (the orange line), we replace the time series of investment, its price, and depreciation rate without IPP with their counterparts including only artistic originals. This produces the purple line labeled " + artistic originals". The inclusion of the artistic originals component has little effect on the behavior of LS. However, including R\&D in a similar fashion produces a larger decline in LS (the green line in the same figure), which accounts for about two-thirds of the total decline by 2013. The gap between the green line and the post-revision blue line is accounted for by adding the software component of the IPP.

Panel (c) of Figure 9 plots the change in LS upon the inclusion of each component separately. The total decline in the LS due to IPP capitalization is depicted by a continuous downward trend that registers a drop of about 5 LS points by 2010 (see the magenta line in panel (c) of Figure 9). Of the three IPP components, the effect from the capitalization of $R \& D$ is the largest. $R \& D$ alone generates $87 \%$ of the total LS decline generated by IPP capitalization until 1965 . After that year the role of software becomes increasingly important: R\&D accounts for $73 \%$ of the decline in the 1970 s, $71 \%$ in the 1980 s, $65 \%$ in the 1990 s, and $57 \%$ of the decline in the 2000 s. The decreasing effect of $R \& D$ is generated by the increasing role of software that accelerated in the 1960 s and accounts for almost $30 \%$ of the LS decline by the 2000 s.

\subsection{Effects of IPP Capitalization on Labor Share: Private and Government IPP}

This section examines the role of the private and government sectors separately. We start by showing the importance of private and government IPP in aggregate investment in panel (a) of Figure 10. Both private and government IPP investments slowly rise from the late 1940s to the mid-1960s, although this share always remains below $10 \%$ for both sectors. However, since the mid-1980s, the private IPP investment accelerates to reach $20 \%$ of aggregate investment by 2013, while the government IPP investment remains somewhat steady around $6 \% .{ }^{38}$

\footnotetext{
${ }^{37}$ To conduct this exercise, note that the private fixed investment by type of IPP is available from NIPA Table 5.3.5 and the government investment from NIPA Table 3.9.5. The price of investment by type of IPP is from NIPA Table 5.3.4. Net stock of capital and the depreciation of fixed assets by type of IPP are available from Table 2.1 and 2.4 for private sector and 7.1 and 7.3 for government in FAT.

${ }^{38}$ That is, while the private and government sector show roughly an equal share of IPP investment until the late 1960s, the share of IPP investment in the private sector is 3.3 times larger than in the government sector by 2013 . However, note that within sectors IPP contributes to $25 \%$ of total private investment and $32 \%$ of total government investment. The increase in the private IPP share of aggregate investment is due to a continuous
} 
As shown in panel (b) of Figure 10, removing the IPP capitalization in the private sector (analogous to Section 3.3 for the entire economy), we find that the LS decline is largely alleviated. That is, the reduction in the LS that comes from the private sector only is given by the distance between the blue line and the green line in that panel. We present this reduction as a percentage of the total decline in the LS in panel (c) of Figure 10. The capitalization of private IPP investment accounts for an increasingly large fraction of the decline in the LS since the mid-1960s. In 2000, about $73 \%$ of the decline in LS is due to the capitalization of the private sector IPP alone.

\subsection{IPP Capitalization and the Corporate Sector}

A useful feature of the corporate sector is that it minimizes the role of ambiguous income in the computation of the LS (i.e., there is no proprietors' income), a feature exploited, for instance, by Boldrin and Fernández-Villaverde (2005), Boldrin and Peralta-Alva (2009), and Karabarbounis and Neiman (2014a). ${ }^{39}$ For the corporate sector, we compute the LS by dividing the compensation of employees (i.e., the income accruing to employees, such as wages, salaries, employers' contributions for social insurance, and other labor income) by the gross value added, which consists of the consumption of fixed capital, compensation of employees, taxes on production and imports less subsidies, and net operating surplus. ${ }^{40,41}$

The corporate LS, constructed from post-revision data, is described in panel (a) of Figure 11. This LS remains steady around a value of 0.63 from the late 1940 s to the mid-1970s and, as noted by Karabarbounis and Neiman (2014a), it exhibits a decline since the mid-1970s, from 0.63 in 1975 to 0.56 in 2013. ${ }^{42}$ Further, as in our accounting exercise of Section 2.3, we find that removing IPP depreciation also removes about $43 \%$ of the LS decline that occurred between 1975 and 2013.

increase in private $R \& D$ and a fast increase in private software, both reaching around $9 \%$ of aggregate investment by 2013 (panel (a) of Figure B-5 in the online Appendix). Instead, the government R\&D share of aggregate investment decreases from $8 \%$ in mid-1960s to $5 \%$ in the early 2010 s and the government software still remains below $1.2 \%$.

${ }^{39}$ The caveat is that the corporate sector does not account for the entire US economy. Precisely, the corporate sector represents $55 \%$ of GNI in 1948 and $65 \%$ in 2013 . It increases to $71 \%$ in the early 1980 s and decreases to $65 \%$ in the 2000 s.

${ }^{40}$ In turn, net operating surplus consists of net interest and miscellaneous payments, business current transfer payments, and corporate profits.

${ }^{41}$ Here we focus on the joint LS behavior of financial and nonfinancial corporate businesses. See the online Appendix A.3 for data sources and construction. The LS behavior of the entire corporate sector and the nonfinancial corporate sector are similar because the financial corporate sector is relatively small. The gross value added of the financial corporate sector accounts for $4 \%$ of the corporate gross value added; this proportion slowly increases to $12 \%$ toward the end of the sample.

${ }^{42}$ Our corporate LS is identical to the updated LS data supplied by Karabarbounis and Neiman (2014a) for the subperiod 1975 to 2012 (i.e., the green line in panel (a) of Figure 11). 
Note that the corporate sector fixed investment consists of private nonresidential fixed investment and assets. ${ }^{43}$ Panel (b) of Figure 11 shows the investment share of structures, equipment, and IPP in the corporate sector. The share of investment in structures declines from around 35\% in the late 1940 s to a somewhat steady $20 \%$ share since the late 1990 s. Equipment investment accounts for a steady $53 \%$ of total investment until the late 1990 s, after which it starts to decline, reaching $46 \%$ in 2013. This change is explained by an increase in the share of IPP investment from $9 \%$ in the late 1940 s to $27 \%$ in the late 1990 s, reaching $33 \%$ in 2013 . These figures are larger for the corporate sector than for the entire economy (see Figure 2), suggesting a larger IPP capital intensity in the corporate sector, although this is partly due to the fact that the corporate sector does not include residential investment. ${ }^{44}$

The FAT decompose the fixed assets (and their depreciation) of the corporate sector into structures, equipment, and IPP (see the online Appendix A.3). This allows us to assess the effects of IPP capitalization on corporate sector LS in a one-sector model analogous to Section 3.3. The investment prices are those for the entire economy already computed in Section 3.2. The results from the counterfactual exercise of removing IPP capitalization are shown in panel (c) of Figure 11. We find, as was the case for the entire economy, that IPP capitalization completely explains the LS decline in the corporate sector. Basically, the counterfactual LS (orange line in panel (c) of Figure 11) without IPP capitalization displays no visible trend after $1975 .{ }^{45}$

Finally, panel (d) of Figure 11 decomposes the effects of IPP capitalization on corporate LS by sequentially adding to the data without IPP the investment price with IPP, the depreciation rate with IPP, and the investment flow with IPP. As for the entire economy, most of the LS decline in the corporate sector is captured by the IPP investment flow.

\section{IPP Capitalization and Labor Share by Industry}

Our main result is that the LS decline is driven by IPP capitalization. In this section, we investigate which industries are becoming more intense in IPP capital and whether the decline of LS at the industry level can be explained by industry-wide IPP capital intensity.

To start, we plot the output shares of 12 main industries from 1947 to 2013 in Figure $12 .{ }^{46}$

\footnotetext{
${ }^{43}$ That is, the corporate sector does not include components associated with residential investment and/or government investment. It also excludes noncorporate private investment.

${ }^{44}$ See Figure B-4 in the online Appendix for a decomposition of investment shares for the aggregate economy without residential investment.

${ }^{45}$ If at all, LS seems to slightly increase by 2 LS points from the late 1940s to the mid-1970s.

${ }^{46}$ We recognize 12 main industries, 11 of which correspond to the 2-digit North American Industry Classification System (NAICS) codes: agricultural, forestry, fishing and hunting, mining, utilities, construction, durable goods manufacturing, non-durable goods manufacturing, wholesale trade, retail trade, transportation and warehousing,
} 
Of all industries, only services, information, and FIRE (finance, insurance, real estate, rental and leasing) are growing relative to other industries, so their output shares increase, see panel (a) of Figure 12. The fastest-growing industry is services which starts at $13.1 \%$ of the total output in 1947 and grows to 30\%, almost a threefold factor, by 2013. FIRE also shows an important increase in output share from around $12 \%$ in 1947 to $22.6 \%$, almost a twofold factor, in 2013. Information starts low, around $3.2 \%$ and increases by about a 1.5 -fold factor reaching an output share that is still small, 5.5\%, compared with the other growing industries. The output shares of industries that stagnate or decline are found in panel (b) of Figure 12. The industry with the largest decline is clearly manufacturing. The durable goods manufacturing share of output drops from nearly $18 \%$ in the early 1950 s to $7.6 \%$ in 2013 , and the nondurable goods manufacturing share of output drops from $14.3 \%$ in 1947 to $6.9 \%$ in 2013 . In relative terms, it is also important to note the drop in the agricultural share of output from $9.3 \%$ in 1947 to $1.4 \%$ in 2013 . In short, output is moving to services, FIRE and information, and the industries with stagnant or decreasing output shares by 2013 that still represent a large share of output are manufacturing (in durables and nondurables), retail trade, and wholesale trade.

Next, we use additional industry-level data of investment, price of investment, and depreciation from the FAT to construct industry LSs using equation (5) from Section 3.1. ${ }^{47}$ We apply that formula separately to each industry under the assumption that the net return to capital is identical across NAICS industries. The main reason to use this LS construct, in addition to ensure consistent industry classification under NAICS throughout the 1947-2013 period, is that it allows us to study the effects of IPP capitalization on the LS at the industry level, in the same manner that we explored these effects at the aggregate level in Section 3.3. ${ }^{48}$ At the same time, we construct the industry IPP capital intensity by dividing the IPP capital stock by the total capital stock in each industry. We investigate the relationship between LS and the IPP capital intensity

information, and finance, insurance, real estate, rental and leasing. We additionally construct services as the twelfth industry, which includes the following set of 2-digit NAICS code industries: professional and business services, educational services, health care and social assistance, arts, artistic originals and recreation, accommodation and food services, and other services. In Section A.2 in the online Appendix, we further describe the source and sample periods of industry data and some adjustment methods that we apply to the value added data by industry.

${ }^{47} \mathrm{~A}$ nice feature from the FAT is that, unlike NIPA, they consistently use NAICS codes from 1947 to 2013. The change in the industry classification in NIPA makes the construction of a consistent measure of LS over time from NIPA alone unfeasible for some industries, for lack of disaggregated sub-industry data.

${ }^{48}$ For the subperiod 1998-2012 we also construct the NAICS industry LS computed directly from the national income components in NIPA according to Section 2.1; this is not feasible for the pre-1997 years because the NIPA industry classification for those years is based on the Standard Industrial Classification (SIC). We plot industrylevel LS constructed from the FAT data against industry-level LS computed from NIPA in Figure E-4 in the online Appendix. By and large, the two constructs of LS correspond well. Since our model is frictionless, the difference of the model-based LS and the data-based LS is an indicator of frictions beyond what is factored into the price series of investment. 
by industry for two subsample periods, 1947-1999 and 2000-2012 in panel (a) in Figure 13. ${ }^{49}$ This exercise explores whether industries that have grown more in IPP capital intensity have also experienced a decline in LS.

There are three observations to highlight. First, in terms of IPP capital intensity, we find that the industries with the highest intensity are also those that experience larger growth in IPP capital intensity in the 2000s. In addition, these industries consist of six of the seven industries with the highest output share in $2013 .{ }^{50}$ These industries include information and services-that is, two of the three growing industries identified in Figure 12-that respectively grow by about 0.05 and 0.06 IPP capital intensity points from the first to the second subperiod, nondurables and durables manufacturing which respectively grow by 0.166 and 0.088 IPP capital intensity points, and wholesale and retail trade, which respectively grow by 0.080 and 0.030 IPP capital intensity points. Some of these industries, such as nondurables and durables manufacturing and information, have a relatively high level of IPP capital intensity above 0.10 before 2000 , and others such as wholesale trade and services start from IPP capital intensity below 0.06 before 2000. Second, in terms of LS, the largest decline occurs in durables manufacturing by 0.15 LS points, in nondurables manufacturing by $0.08 \mathrm{LS}$ points, in both information and retail trade by 0.07 LS points, and in wholesale trade by 0.04 LS points from the first to the second subperiod. These results represent the first direct empirical evidence of the relationship between the largest growth in IPP capital intensity and the largest declines in LS at the industry level. The largest increases in IPP capital intensity and declines in the LS occur for industries with large initial LS values. Instead, industries with relatively low LS such as agriculture, FIRE, and utilities, barely experience an increase in IPP capitalization and declines in the LS. Finally, only two of the 12 main industries exhibit a positive relationship between IPP capital intensity and LS, transportation and mining.

We also disaggregate the 12 main industries into 47 sub-industries (3 and 4-digits NAICS) for the period 1947-2013. ${ }^{51}$ For each of these subindustries, panel (b) in Figure 13 reports on the vertical axis the difference (i.e., changes in levels) in LS between the pre- and post-2000 years and on the horizontal axis the difference in IPP capital intensity between the pre- and post-2000 years. Our sample largely populates the bottom-right quadrant of that panel suggesting that most subindustries display a decline in their LS associated with an increase in their IPP capital intensity, with very few industries showing a decline in IPP capital intensity and/or an increase in

\footnotetext{
${ }^{49}$ The point break of 2000 is motivated by the fact that, since the ealry 2000 s, we find IPP investment has reached a steady structure of its components, that is, the share of software, $R \& D$, and artistic originals in total IPP investment has remained relatively stable after year 2000; see the discussion in the online Appendix B.

${ }^{50}$ Only FIRE is missing with a high output share but low IPP capital intensity.

${ }^{51}$ See Table E-1 in online Appendix for industry codes and names. Our sample increases to 57 subindustries if we restrict the attention to the post-1970 years, without providing additional insights in our results.
} 
LS (e.g., petroleum and coal products (Sub-24)). For example, chemical products (Sub-25) shows an increase in IPP capital intensity by .26 points and a decline in LS by .06 points and computer and electronic products (Sub-13) shows an increase in IPP capital intensity by .15 points and a decline in LS by .17 points. The results are clear. The general pattern that emerges is that increases in IPP capital intensity go hand in hand with decreases in LS at the subindustry level; a simple regression weighted by subindustries output shares implies that for a .100 points increase in IPP capital intensity, LS declines by .020 points. In all, even with a finer industry classification, we find a negative relationship between LS and IPP capital intensity that is consistent with our main findings for 2-digit NAICS industries described previously.

Finally, when IPP capitalization for each industry is removed in the same fashion as described in Section 3.3, we confirm that the LS of industries that invest in IPP flattens out. These results are shown in Figure 14 for the main industries that invest in IPP—-that is, information, services, nondurable and durable goods manufacturing, wholesale trade and retail trade. ${ }^{52}$ The effects of IPP capitalization on the LS in information industry are large: With IPP capitalization, the LS in information declines from 0.68 in 1947 to 0.50 in 2013, a drop of 0.18 LS points. After removing IPP capitalization, the LS drop in information reduces to 0.06 LS points from 0.71 in 1947 to 0.65 in 2013, and LS displays an increase from 0.60 in the mid-1980s to 0.65 in 2013 . For the services industry the LS starts at 0.86 in 1947 . With IPP capitalization, the LS in services falls to 0.82; without IPP capitalization, LS remains essentially flat and ends at the same 0.86 in 2013. We find similar effects of IPP capitalization on the LS in wholesale trade and retail trade.

So far, we have not discussed the potential effects of globalization. The observed declining LS in the US, especially since the great recession, may also reveal the cumulative effects of outsourcing US manufacturing in the 2000s. ${ }^{53}$ Using the post-revision data, the LS of nondurable goods manufacturing and that of durable goods manufacturing declines by, respectively, 0.20 and 0.25 LS points from 1947 to 2013, representing the two largest LS declines in all industries. Further, at the same time, these two industries have also invested heavily in IPP, especially in the post-2000 period, suggesting a potential relationship between IPP capitalization and LS. Removing the effects from IPP capitalization largely mitigates the decline in LS. For nondurables manufacturing, the LS without IPP decreases by 15 percentage points from 1947 to 1984, but it actually increases by 5 percentage points from 1985 to 2013, netting a 10\% decline over the entire sample. For durable goods manufacturing, LS without IPP declines by 10 percentage points from 1947 to 1983 and thereafter remains constant until the end of our sample. In sum, IPP capital drives the LS of the manufacturing industries down. From our perspective, it

\footnotetext{
${ }^{52}$ For industries that do not invest in IPP the effects of removing IPP capitalization are, obviously, negligible.

${ }^{53}$ See Elsby et al. (2013) for a macroeconomic perspective and Autor et al. (2013) for a microeconomic perspective.
} 
seems natural to interpret globalization as a source generating IPP investment. That is, firms outsource the routine process of their production, which allows them to focus on the innovation process; although we acknowledge that this argument deserves further exploration. ${ }^{54}$ Under this interpretation, one channel through which the relocation of production units to countries with low labor costs can affect the US LS is through increases in the US IPP capital intensity, particularly, in the manufacturing industry.

\section{What Does IPP Capitalization Imply For the US?}

As we have shown, when IPP capitalization is accounted for, the decline of the LS starts as early as the late 1940s. Hence, any model of the US economy featuring IPP capital needs to allow for the possibility of a nonconstant LS, at least in its transitional dynamics. To explore this point, we adopt a two-sector model with one final good sector and one IPP investment good sector, a framework that mimics that in McGrattan and Prescott $(2010,2012) .{ }^{55}$ The sole difference is that we allow the LS to differ across the two sectors.

\subsection{A Simple Two-Sector Model}

The final good sector produces a consumption good, the numéraire, using labor, $l_{1, t}$, traditional capital (i.e., structures and equipment), $k_{1, t}$, and IPP capital, $d_{t}$ :

$$
y_{t}=A_{1, t}\left(k_{1, t}\right)^{\theta_{1}}\left(d_{t}\right)^{\phi_{1}}\left(l_{1, t}\right)^{1-\theta_{1}-\phi_{1}} .
$$

The IPP sector produces an IPP investment good using labor, $l_{2, t}$, traditional capital, $k_{2, t}$, and IPP capital, $d_{t}$ :

$$
x_{t}^{d}=A_{2, t}\left(k_{2, t}\right)^{\theta_{2}}\left(d_{t}\right)^{\phi_{2}}\left(l_{2, t}\right)^{1-\theta_{2}-\phi_{2}} .
$$

Note that the traditional capital and labor are split across the two sectors: $k_{t}=k_{1, t}+k_{2, t}$ and $l_{t}=l_{1, t}+l_{2, t}$. However, IPP capital is shared across sectors, as in McGrattan and Prescott (2010).

Investment in traditional capital is produced via a linear technology from the consumption good: $x_{t}^{k}=v_{t}^{k} i_{t}^{k}$. Analogously, IPP investment is $x_{t}^{d}=v_{t}^{d} i_{t}^{d}$, where $v_{t}^{d}$ is the inverse of the

\footnotetext{
${ }^{54}$ Bloom et al. (2011), using a firm-level panel data set from the EU, show Chinese import competition led to increased innovation within firms and reallocated employment between firms toward more technologically advanced firms. Petri Böckerman and Mika Maliranta (2012) find similar effects of globalization on employment that shift employment from firms with high labor shares toward firms with low labor shares in a panel of Finnish firms.

${ }^{55}$ See also a more recent discussion in McGrattan and Prescott (2014).
} 
relative price of IPP invesment and captures ISTC in that sector. The laws of motion of the traditional and IPP capital are given by

$$
\begin{aligned}
& k_{t+1}=\left(1-\delta_{k}\right) k_{t}+x_{t}^{k}, \\
& d_{t+1}=\left(1-\delta_{d}\right) d_{t}+x_{t}^{d},
\end{aligned}
$$

where $\delta_{k}$ and $\delta_{d}$ are the deprecriation rates of the structures and equipment capital and IPP. Note that even though the depreciation rate in each sector is constant over time, as long as the depreciation rates differ, the aggregate depreciation rate will vary according to the compositional change in the two types of capital, consistent with our findings in Section 3.2.2.

The LSs in the final good sector, $1-\theta_{1}-\phi_{1}$, and in the IPP sector, $1-\theta_{2}-\phi_{2}$, are constant. The aggregate labor share, $\mathrm{LS}_{t}$, can be expressed as an average of the two sector-specific LSs weighted by the output shares of the two sectors ${ }^{56}$ :

$$
\mathrm{LS}_{t}=\left(1-\theta_{1}-\phi_{1}\right) \frac{y_{t}}{y_{t}+\frac{1}{v_{t}^{d}} x_{t}^{d}}+\left(1-\theta_{2}-\phi_{2}\right) \frac{\frac{1}{v_{t}^{d}} x_{t}^{d}}{y_{t}+\frac{1}{v_{t}^{d}} x_{t}^{d}}
$$

Our empirical results at the industry level suggest that the LS declines with IPP capital intensity (see previous Section). Given that the IPP is often conducted in-house, industries that invest more in IPP are also likely to be those producing IPP. This suggests that the LS in the IPP sector may well be lower than that in the rest of the economy, that is, $1-\theta_{2}-\phi_{2}<1-\theta_{1}-\phi_{1}$, which can be achieved with $\theta_{1}=\theta_{2}$ and $\phi_{1}<\phi_{2}$. Such calibration is consistent with the aggregate results in Figure 6 implying that a higher IPP output (i.e., investment) share in aggregate output leads to a higher aggregate IPP capital share of output while the no-IPP capital share (i.e., structures and equipment) remains constant. This mechanism declines the aggregate LS in response to increases in the IPP output share. If, however, the ratio between IPP and non-IPP output remains constant, the aggregate LS must be constant as well. The fact that we do not observe such steady behavior in the US LS suggests, in the light of this model, that the US economy is still in transition to a larger IPP sector.

\subsection{Discussion and Further Challenges}

Should we use the LS with or without IPP capitalization? The answer is straightforward: It

\footnotetext{
${ }^{56}$ If the factor shares are identical across sectors (as is in McGrattan and Prescott (2010)), that is, $\theta_{1}=\theta_{2}$ and $\phi_{1}=\phi_{2}$, then the aggregate LS will be constant. In their Technical Appendix, McGrattan and Prescott (2010) allow for differences in the output shares of non-IPP and IPP capital across sectors (i.e., $\theta_{1} \neq \theta_{2}$ and $\phi_{1} \neq \phi_{2}$ ), while keeping the LS identical across sectors (i.e., $1-\phi_{1}-\theta_{1}=1-\phi_{2}-\theta_{2}$ ).
} 
depends on the model one has in mind. For models without IPP investment, one should ignore IPP capitalization and, hence, LS is trendless for the past 65 years.

That said, omitting IPP investment implies ignoring $26 \%$ of aggregate and $38 \%$ of nonresidential investment by 2013. Such a large change in the composition of investment in the US economy translates into a shift of the economy's technological structure to much higher IPP output. And the trend is still continuing. Investment in software and R\&D, in particular, is changing the very best and largest firms in the US, even more so in the most recent years (see Section 3.5). The increase in aggregate IPP investment is created, in a large part, by firms such as Amazon, Microsoft, Intel, Merck \& Co., Johnson \& Johnson, General Motos, Google and Cisco that lead the innovative process. Take Amazon, for example. The level of logistic efficiency in Amazon's fulfillment centers is unimaginable without its investment in infrastructure software. New products and technologies created by Amazon-such as the electronic visual display that underlies Kindle and the unmanned aerial vehicle (or "drone") —usually take years of development in the in-house R\&D labs before commercialization. ${ }^{57}$

This suggests that a fruitful approach to understanding the US economy is one that recognizes the increasing importance of the IPP sector. In the previous section, we showed that a standard two-sector model featuring IPP capital along the lines of McGrattan and Prescott $(2010,2012)$ that further allows for differential LS across sectors is able to capture the decline in the aggregate LS. This setting recognizes LS decline as a result of a process of structural transformation to a larger IPP sector.

Two further challenges arise from current data limitations. First, BEA is likely to fall short in accounting for the entire set of IPP capital. While BEA investment accounts incorporate software, $\mathrm{R} \& \mathrm{D}$, artistic originals, they leave out other recognized sources of IPP such as brand equity and organizational capital. Under the direct data approach implemented by BEA to measure IPP, there are good reasons for such choice because the capitalization of these additional IPP components requires series of investment and depreciation rates that are either not readily available or do not exist. The literature has explored alternatives to get around this limitation in the data. McGrattan and Prescott $(2005,2010)$ use the structure of their economic model to recover series of aggregate IPP capital (a latent variable in their setting) such that other model moments-that do not direcly involve IPP_are consistent with their observable counterparts. ${ }^{58}$ Their exercise

\footnotetext{
${ }^{57}$ In a recent interview with Charlie Rose, Jeff Bezos, the founder and CEO of Amazon, estimates their drones can deliver $86 \%$ of total Amazon purchases (i.e. weighing up to 5 lbs.). Like Amazon, 3D Robotics, DJI, Google, and several other companies that invest in drone technology are awaiting changes in airspace regulation. The interview was released December 1, 2013, at CBS News 60 Minutes-Business: http://www. cbsnews.com/news/ amazons-jeff-bezos-looks-to-the-future.

${ }^{58}$ Alternatively, Hall (2000) uses stock market data to estimate intangible capital stock with a model that
} 
gives us a unique opportunity to compute how much BEA currently captures of total IPP using a measure of total IPP obtained with an entirely different methodology. If we focus on the corporate sector, we find that BEA IPP capital represents $14.1 \%$ of total capital in the late 1990 s, while this figure is $29.4 \%$ in McGrattan and Prescott (2005). In terms of capital income shares, we find that BEA IPP capital accounts for $4.5 \%$ of total income in the 2000 s, while this figure is $7.6 \%$ in McGrattan and Prescott (2010). These comparisons confirm the notion that BEA captures a fraction, i.e., between $48 \%$ and $59 \%$, of total IPP.

To address this issue, at least partially, we extend the BEA accounts to incorporate advertising capital, an important dimension of branch equity. ${ }^{59}$ We follow Hall (2014) and use the investment series for advertising largely based on the work by Douglas Galbi. ${ }^{60}$ We find that advertising accounts for roughly a constant 9\% of aggregate investment from 1947 to 2010 . The share of advertising in aggregate investment is the largest of all IPP components until the mid-1950s and still at least as large as software and slighlty below R\&D by $2010 .{ }^{61}$ Assuming a depreciation rate of .5, the median in the set of estimates in Bagwell (2007), we recover advertising capital. Finally, we extend our exercise in Section 3.4 to explore the effects of advertising capitalization on the LS. We find that advertising paralelly shifts the LS down around 0.015-0.017 LS points from 1947 to 2010 but does not strengthen (or alleviate) the decline of LS.

Finally, the second limitation from the data is that, even though preliminary results from industry data in Section 4 are consistent with our interpretation of the declining LS, a direct test requires direct measures of output and factor income shares of the IPP sector, and we cannot separately identify these LSs across sectors in the current data. One option is to use the InputOutput Tables in a manner similar to Valentinyi and Herrendorf (2008), classify commodities into a new IPP sector and compute the capital and labor share for each dollar of IPP output. Alternatively, the BEA has already contemplated the possibility of creating an R\&D industry in the US industry accounts. ${ }^{62}$ In preparing for the 2013 NIPA revision, the BEA has built a R\&D satellite account that provides detailed statistics on the nominal and real R\&D investment (i.e., $R \& D$ output), the $R \& D$ capital stock, the rate of return, and the depreciation rate of $R \& D$

incorporates such features.

${ }^{59}$ This exercise is described in detail in the online Appendix F. Of the set of IPP components currently omitted by BEA, advertising is perhaps the IPP component for which there are, till some extent, more available measures of investment and depreciation, see Bagwell (2007), McGrattan and Prescott (2014) and Hall (2014).

${ }^{60}$ These series consist of aggregate advertising expenditures in newspapers, other periodicals, magazines, direct mail, farm publications, business papers, billboards, out of home yellow pages, radio, television, broadcast TV, cable and internet. They are available at purplemotes.net, http://www.galbithink.org/cs-ad-dataset.xls (as of January 2014).

${ }^{61} \mathrm{McGrattan}$ and Prescott (2014) also find large expenditures in advertising that are similar to those of R\&D using Compustat data.

${ }^{62}$ See Section V of "R\&D Satellite account: Preliminary Estimates" (on page 62 of Okubo et al. (2006)). 
capital. ${ }^{63}$ Using the performer-based data of the National Science Foundation surveys, from which the R\&D satellite account itself draws heavily, it should be possible to combine wages and compensations of $R \& D$ personnel to form the basis of a measure of labor income in the $R \& D$ sector. ${ }^{64}$ If the BEA could expand such effort on the R\&D satellite account to all components of IPP, we would be able to construct the LS for the IPP sector the same way we construct the LS at the industry level. We call for an effort from the statistical agencies to consolidate the production of IPP into an integral account that differentiates the IPP sector from the rest of the economy. The potential gain from such cleaner IPP accounting framework in understanding the current US economic model could be huge.

\section{Conclusion}

Using new insights from the post-2013 BEA revision data that capitalize IPP, we show that the decline in the labor share of national income during the past 65 years can be attributed entirely to IPP capital. Further, the somewhat weaker and more recent decline in the labor share displayed by the pre-revision data is analogously explained by the capitalization of software, which was the only IPP component capitalized before the revision. The decline of the labor share should therefore be seen as the result of a shift toward a more IPP-intensive economy, a shift induced by continuing technological change. It is such changes and its implications on income distribution across sectors and factors of production that should be modeled.

To better inform modeling choices, we believe the BEA can make further progress on data organization. Specifically, separating firms, or units of firms that specialize in the production of IPP, to form an IPP industry will help clarify a number of issues ranging from the factor shares of income in the IPP sector to the economic relation between the IPP sector and the rest of the economy. So far, our analysis on the labor share across industries ranked by IPP capital intensity suggests that the labor share in the IPP sector is likely to be lower than that of the non-IPP sector, which is consistent with the secular labor share decline of an economy that is becoming more IPP capitalized over time.

Looking ahead, while we have focused on the secular behavior of US data and across its industries, firm-level analysis and multicountry analysis pose interesting challenges for further research. For example, exporting IPP capital to China could potentially reduce the Chinese labor share. Further, we also confirmed the presence of large and persistent cyclical fluctuations in factor

\footnotetext{
${ }^{63}$ For a detailed summary of the BEA's methodology of estimating the output, its price, and the depreciation of R\&D, see online Appendix A.4.

${ }^{64}$ These expenditure data are used in the BEA's construction of an input-cost price index of R\&D output, which later gave way to an alternative output price index believed to better capture the productivity increase of R\&D.
} 
shares that are not altered by IPP capitalization and that, hence, still beg for an explanation. Finally, while we have not attempted to link labor share and economic inequality (see recent discussions in Krusell and Smith (2014) and Karabarbounis and Neiman (2014b)), the fact that IPP capital is behind the US labor share decline suggests that an explanation of the joint dynamics between the labor share and inequality needs to explicitly incorporate entrepeneurial agents and activities that generate IPP.

\section{References}

Acemoglu, D. and Robinson, J. A. (2014). The Rise and Fall of General Laws of Capitalism. Journal of Economic Perspectives, forthcoming.

Autor, D. H., Dorn, D., and Hanson, G. H. (2013). The china syndrome: Local labor market effects of import competition in the united states. American Economic Review, 103(6):212168.

Bagwell, K. (2007). The Economic Analysis of Advertising, volume 3 of Handbook of Industrial Organization, chapter 28, pages 1701-1844. Elsevier.

Bloom, N., Draca, M., and Reenen, J. V. (2011). Trade Induced Technical Change? The Impact of Chinese Imports on Innovation, IT and Productivity. NBER Working Paper No. 16717.

Boldrin, M. and Fernández-Villaverde, J. (2005). A Theory of Growth Cycles. www. micheleboldrin.com/Papers/all_capital5.pdf.

Boldrin, M. and Peralta-Alva, A. (2009). What Happened to the U.S. Stock Market? Accounting for the Past 50 Years. Federal Reserve Bank of St. Louis Review, 91(6):627-46.

Bonnet, O., Bono, P.-H., Chapelle, G., and Wasmer, E. (2014). Does Housing Capital Contribute to Inequality? A Comment on Thomas Piketty's Capital in the 21st Century. Sciences Po Economics Discussion Papers 2014-07, Sciences Po Departement of Economics.

Bridgman, B. (2014). Is Labor's Loss Capital's Gain? Gross versus Net Labor Shares. BEA Working Paper 2014-10.

Cooley, T. F. and Prescott, E. C. (1995). Economic Growth and Business Cycles. In Cooley, T. F., editor, Frontiers of Business Cycle Research. pp. 1-38. Princeton University Press, Princeton, NJ.

Corrado, C., Hulten, C., and Sichel, D. (2009). Intangible Capital and U.S. Economic Growth. Review of Income and Wealth, 55(3):661-685.

Cummins, J. and Violante, G. L. (2002). Investment-Specific Technical Change in the U.S. (19472000): Measurement and Macroeconomic Consequences. Review of Economic Dynamics, 5:243-284. 
Elsby, M., Hobijn, B., and Sahin, A. (2013). The Decline of the U.S. Labor Share. Brookings Papers on Economic Activity, 47(2(Fall)):1-63.

Fernández-Villaverde, J. (2014). Anxieties of Fairness, A Review of Capital in the First Century by T. Piketty. First Things.

Fisher, J. D. (2006). The Dynamic Effects of Neutral and Investment-Specific Technology Shocks. Journal of Political Economy, 114(3):413-451.

Gollin, D. (2002). Getting Income Shares Right. Journal of Political Economy, 110(2):458-474.

Gomme, P. and Rupert, P. (2007). Theory, Measurement and Calibration of Macroeconomic Models. Journal of Monetary Economics, 54(2):460-497.

Greenwood, J., Hercowitz, Z., and Krusell, P. (1997). Long-Run Implications of InvestmentSpecific Technological Change. American Economic Review, 87(3):342-62.

Hall, R. E. (2000). e-Capital: The Link between the Labor Market and the Stock Market in the 1990s. Brookings Papers on Economic Activity, 2:73-118.

Hall, R. E. (2014). What the Cyclical Response of Advertising Reveals about Markups and other Macroeconomic Wedges. NBER Working Papers No. 18370.

Hsieh, C.-T. and Klenow, P. J. (2007). Relative Prices and Relative Prosperity. American Economic Review, 97(3):562-585.

Jones, C. I. (2014). The Macroeconomics of Piketty. Journal of Economic Perspectives, forthcoming.

Kaldor, N. (1957). A Model of Economic Growth. The Economic Journal, 67(268):591-624.

Karabarbounis, L. and Neiman, B. (2014a). The Global Decline of the Labor Share. Quarterly Journal of Economics, 129(1):61-103.

Karabarbounis, L. and Neiman, B. (2014b). Capital Depreciation and Labor Shares Around the World: Measurement and Implications. NBER Working Papers No. 20606.

Krusell, P. and Smith, A. A. (2014). Is Piketty's "Second Law of Capitalism" Fundamental? http://aida.wss.yale.edu/smith/piketty1.pdf.

McCulla, S. H., Holdren, A. E., and Smith, S. (2013). Improved Estimates of the National Income and Product Accounts. Survey of Current Business, pages 14-45.

McGrattan, E. R. and Prescott, E. C. (2005). Taxes, Regulations, and the Value of U.S. and U.K. Corporations. Review of Economic Studies, 72(3):767-796.

McGrattan, E. R. and Prescott, E. C. (2010). Unmeasured Investment and the Puzzling U.S. Boom in the 1990s. American Economic Journal: Macroeconomics, 100(4):1493-1522. 
McGrattan, E. R. and Prescott, E. C. (2012). The Labor Productivity Puzzle. In L. Ohanian, J. T. and Wright, I., editors, Government Policies and the Delayed Economic Recovery, pages 115-154. Hoover Institution Press.

McGrattan, E. R. and Prescott, E. C. (2014). A Reassessment of Real Business Cycle Theory. American Economic Review, 104(5):177-82.

Okubo, S., Robbins, C., Moylan, C., Silker, B., Schultz, L., and Mataloni, L. (2006). Preliminary Estimates of R\&D for 1959-2002. Effect on GDP and Other Measures. Bureau of Economic Analysis: Washington.

Petri Böckerman and Mika Maliranta (2012). Globalization, Creative Destruction, and abour Share Change: Evidence on the determinants and Mechanisms from Longitudinal Plant-level Data. Oxford Economic Papers, 64:259-280.

Piketty, T. (2014). Capital in the Twenty-First Century. Belknap Press of Harvard University Press, Cambridge, MA.

Piketty, T. and Zucman, G. (2014). Capital is Back: Wealth-Income Ratios in Rich Countries, 1700-2010. The Quarterly Journal of Economics, pages 1255-1310.

Prescott, E. C. (1986). Theory Ahead of Business-Cycle Measurement. Federal Reserve Bank of Minneapolis Quarterly Review, 10(4):9-22.

Restuccia, D. and Urrutia, C. (2001). Relative Prices and Investment Rates. Journal of Monetary Economics, 47(1):93-121.

Ríos-Rull, J. V. and Santaeulàlia-Llopis, R. (2010). Redistributive Shocks and Productivity Shocks. Journal of Monetary Economics, 57(8):931-948.

Ríos-Rull, J.-V., Schorfheide, F., Fuentes-Albero, C., Kryshko, M., and Santaeulalia-Llopis, R. (2012). Methods Versus Substance: Measuring the Effects of Technology Shocks. Journal of Monetary Economics, 59(8):826-846.

Rognlie, M. (2014). A Note on Piketty and Diminishing Returns to Capital. http://www.mit. edu/ mrognlie/piketty_diminishing_returns.pdf.

Valentinyi, A. and Herrendorf, B. (2008). Measuring Factor Income Shares at the Sector Level. Review of Economic Dynamics, 11(4):820-835.

Williamson, S. (2014). Piketty/Poverty. http://newmonetarism.blogspot.com/2014/11/ pikettypoverty.html. 
Figure 1: US Labor Share, BEA 1947-2013

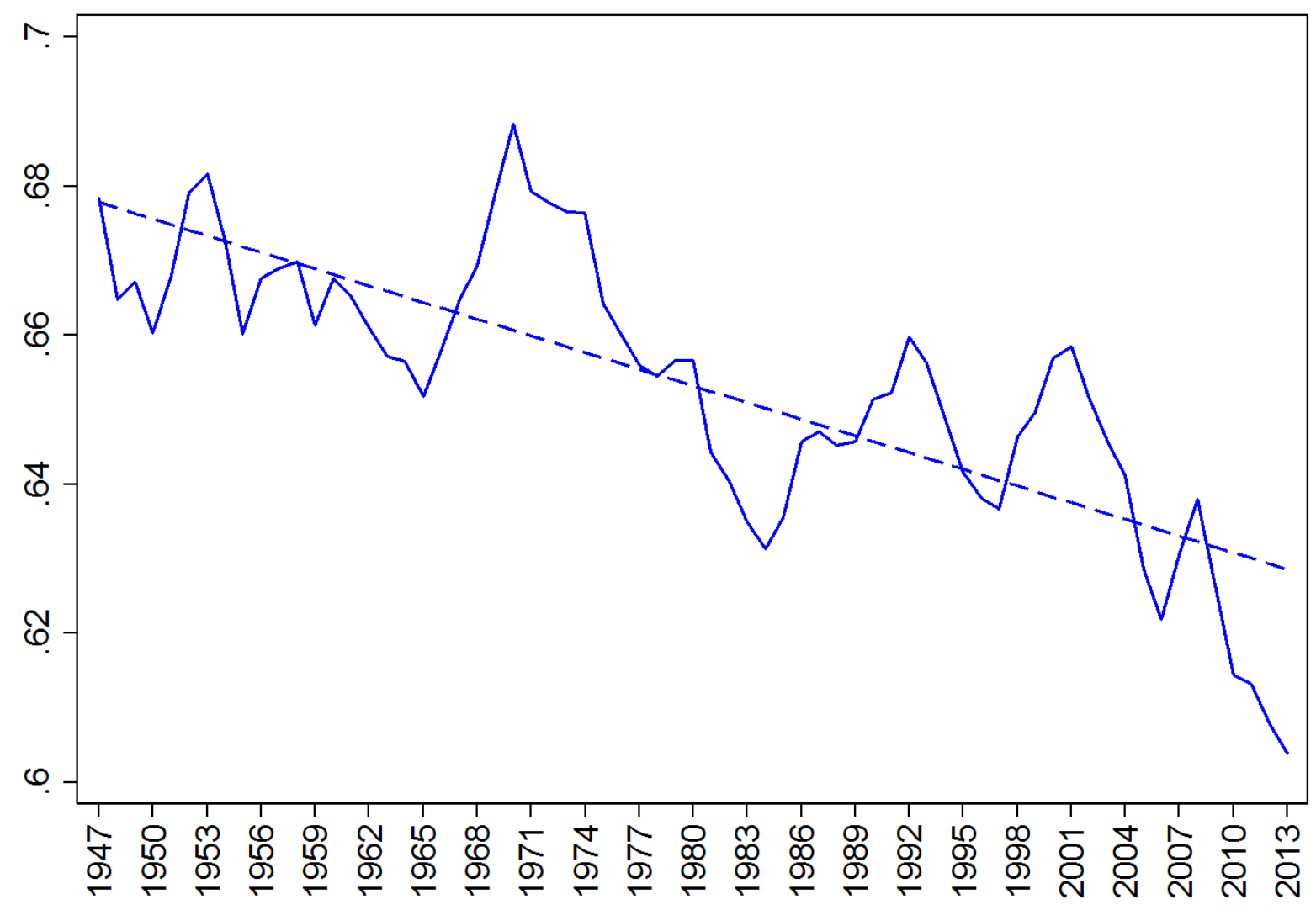

Notes: The labor share of income refers to the benchmark definition described in Section 2.1 and uses only post2013 BEA revision data. The sample period is 1947-2013. The dashed line is a fitted linear trend with an absolute decline of $7.4 \%$ LS points, i.e., from a LS of .678 in 1947 to .603 n 2013. All variables used in computations are in nominal terms. 
Figure 2: Structures, Equipment and IPP Investment Shares, BEA 1947-2013

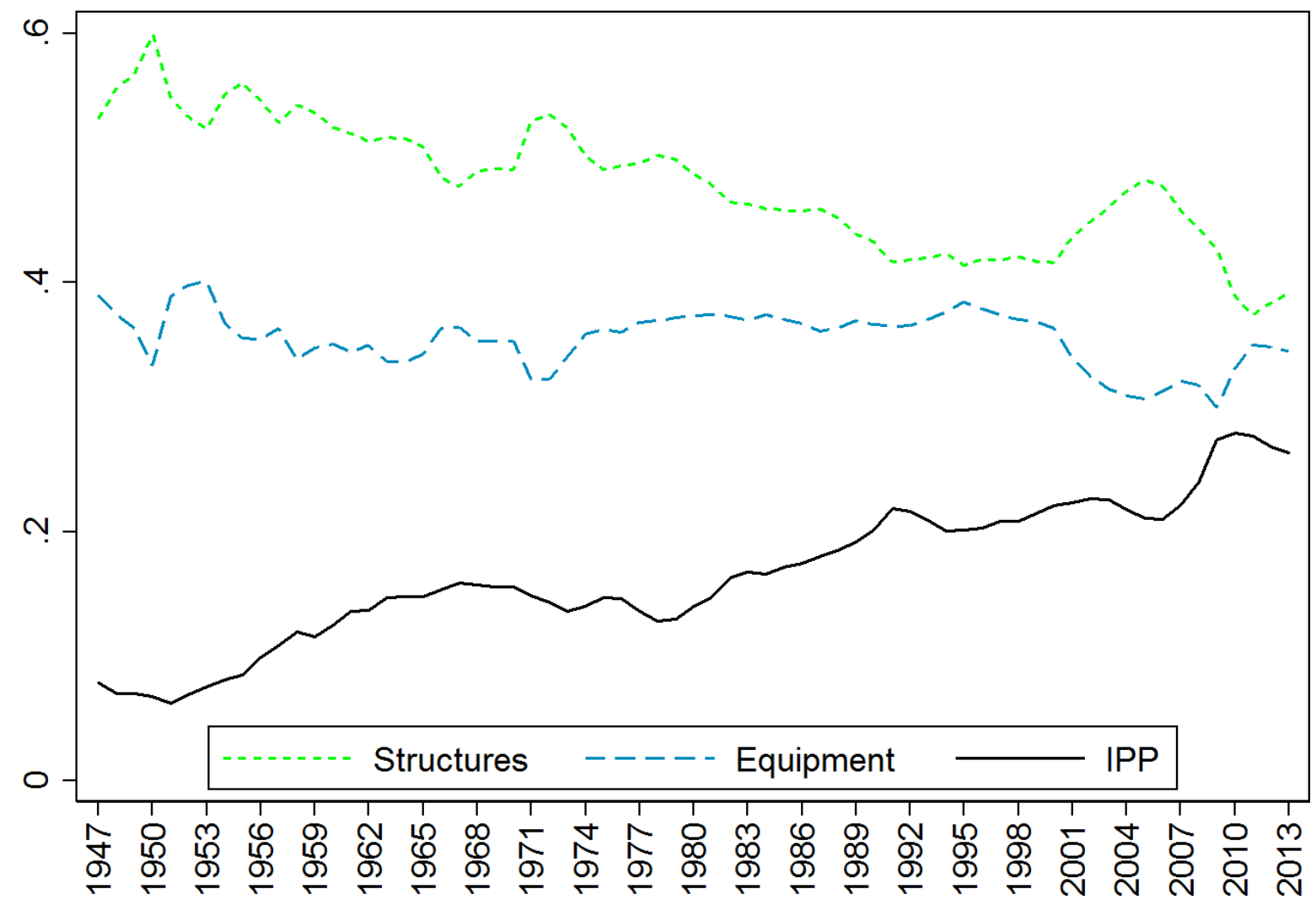

Notes: The investment shares are in terms of aggregate investment that includes both private and government investment and both residential and nonresidential investment. See data construction details in Section 3.2. 
Figure 3: Pre- vs. Post-2013 BEA Revision Data: Labor Share and Its Components

(a) Labor Share, US 1947-2013

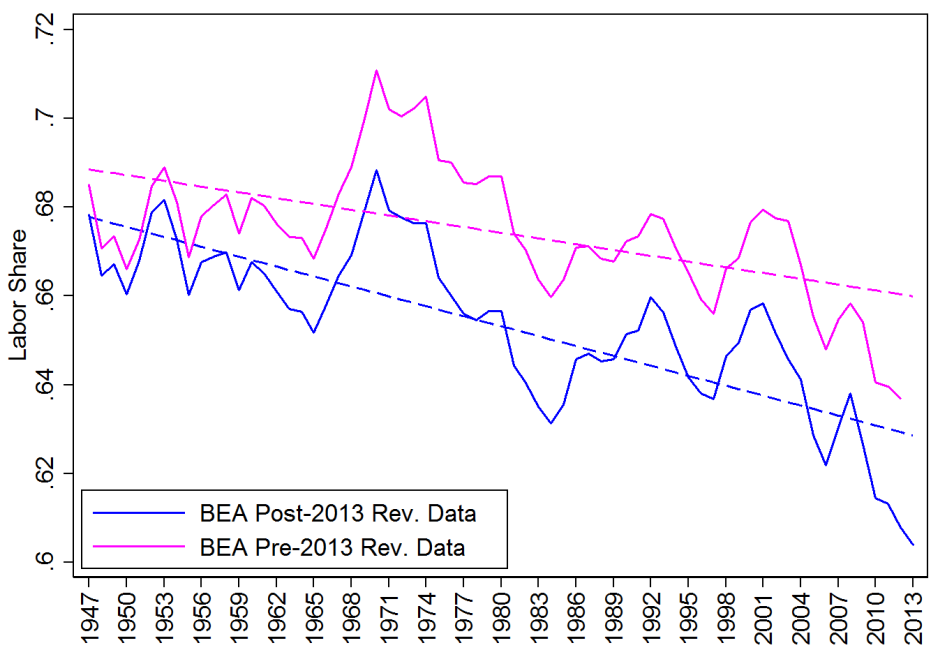

$\stackrel{\oplus}{\infty}$

(c) Output and Labor Income

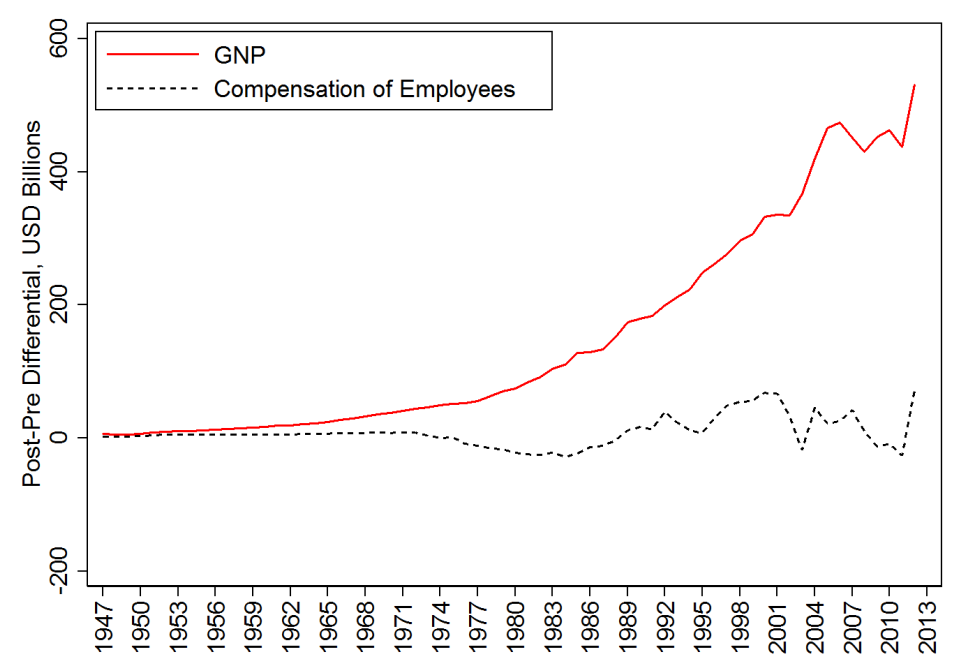

(b) Output, Capital Income and Depreciation

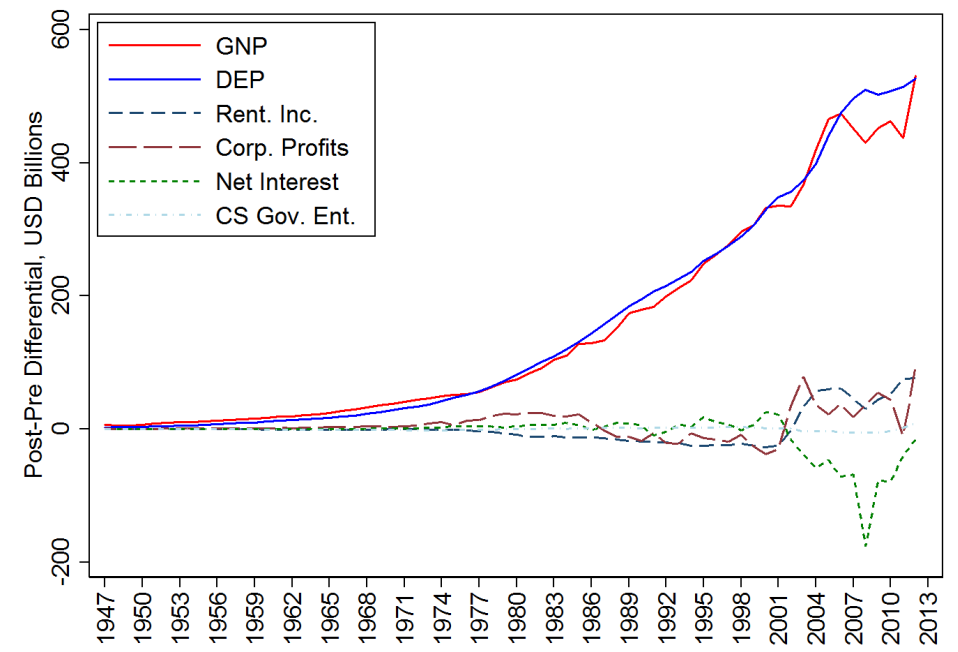

(d) Output and Ambiguous Factor Income

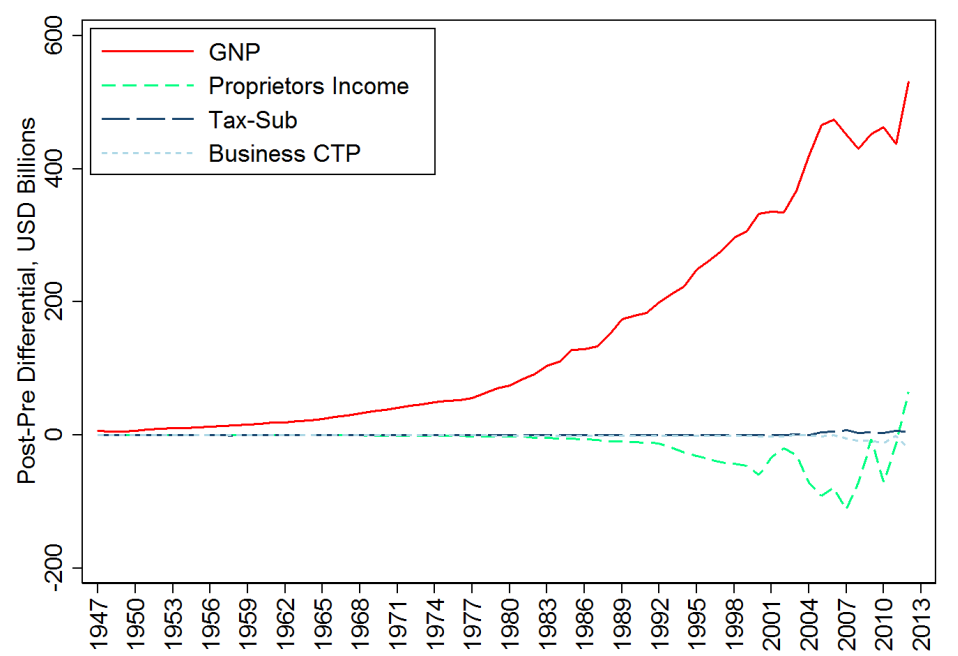

Notes: The labor share of income in panel (a) is constructed using the benchmark definition described in Section 2.1. The 'Pre-Post Differential' reported in panel (b), (c) and (d) are defined as post-2013 BEA revision data minus pre-2013 BEA revision data, in USD Billions. All variables are in nominal terms. 
Figure 4: IPP Depreciation and Labor Share, BEA 1947-2013

(a) Labor Share Net of IPP Depreciation

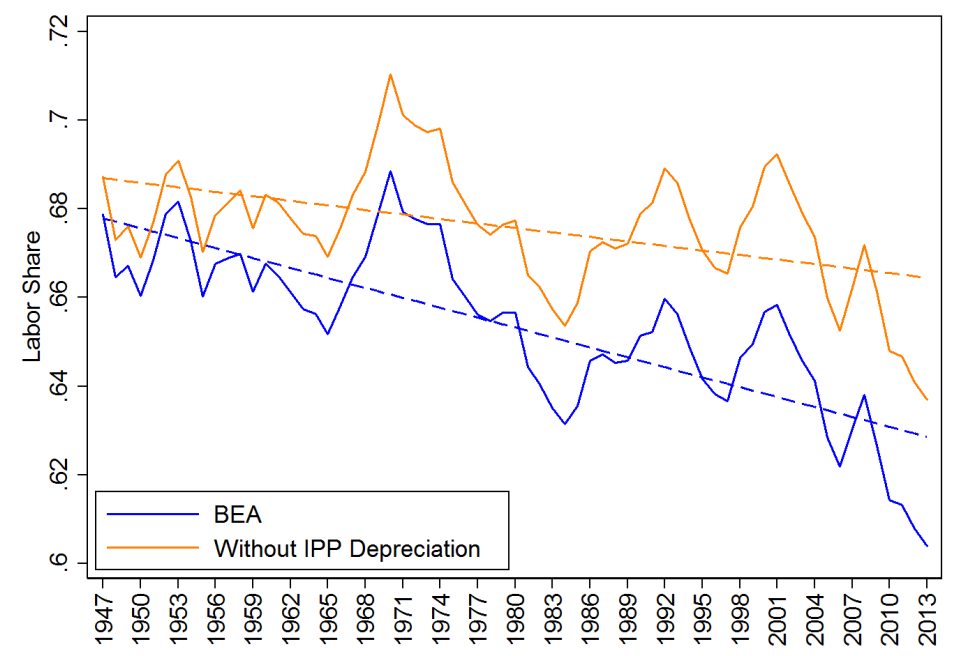

(b) Labor Share Net of Software and non-Software IPP Depreciation

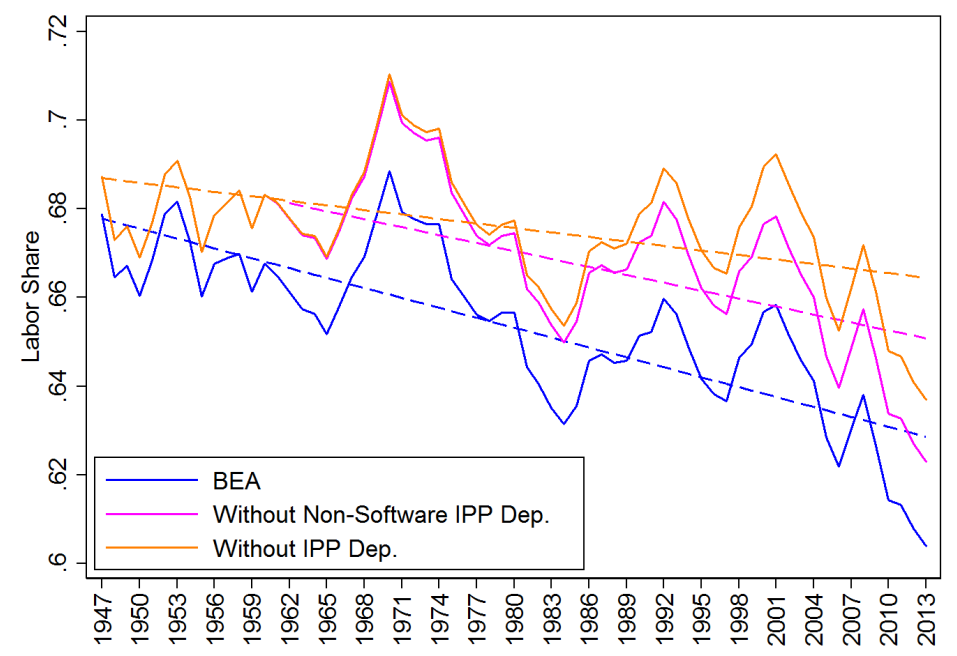

(c) IPP Depreciation vs. Piketty and Zucman (2014), 1975-2010

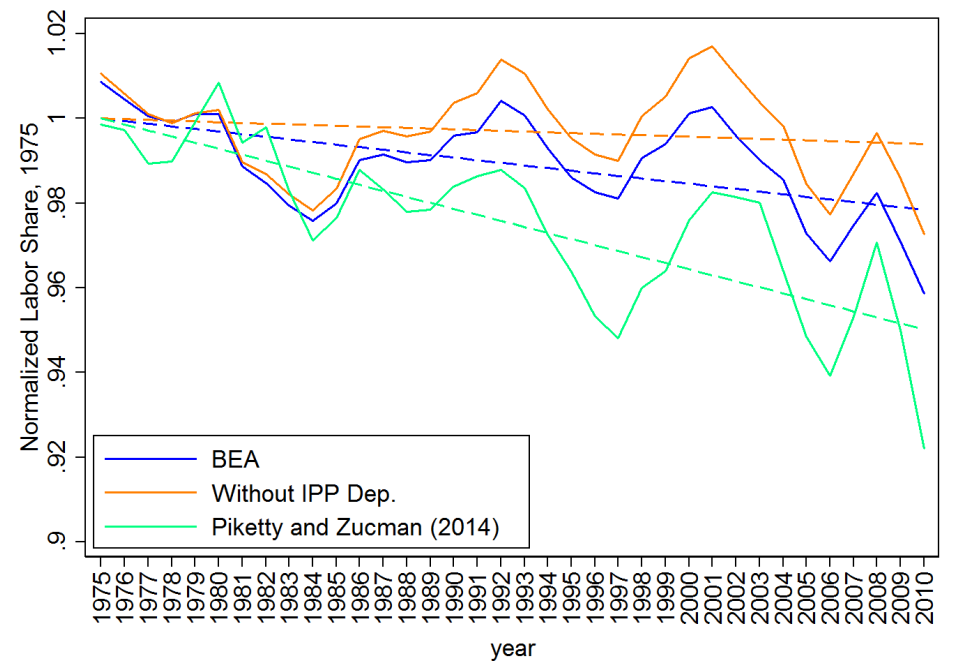

Notes: Benchmark labor share is defined in Section 2.1. In panel (a), labor share without IPP depreciation uses post-2013 revision FAT data to remove, from capital income and from GNP, the increase in depreciation solely generated by IPP, see Section 2.3. Analogously, in panel (b), for labor share without non-software IPP depreciation we solely remove non-software IPP depreciation from the computation of labor share, see Section 2.3. The labor share in Piketty and Zucman (2014) and Piketty (2014) reported in panel (c) is taken from their online appendix in '.xls' form, see more discussion in Section 2.3. 
Figure 5: Effects of IPP Capitalization on Aggregate Investment, Its Price and Depreciation Rate

(a) Aggregate Investment With and Without IPP

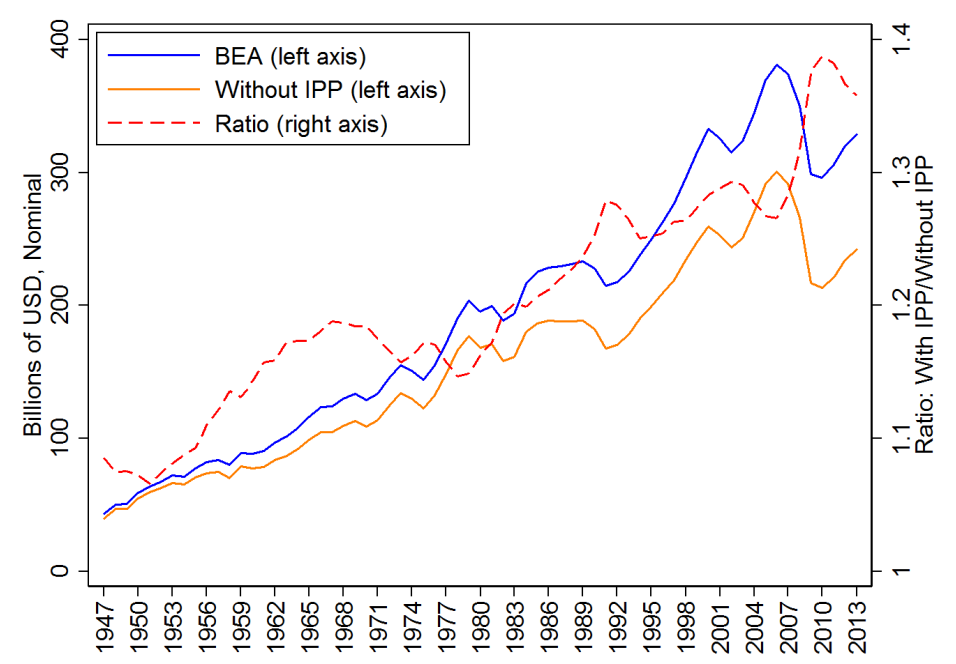

(b) Relative Price of Investment With and Without IPP

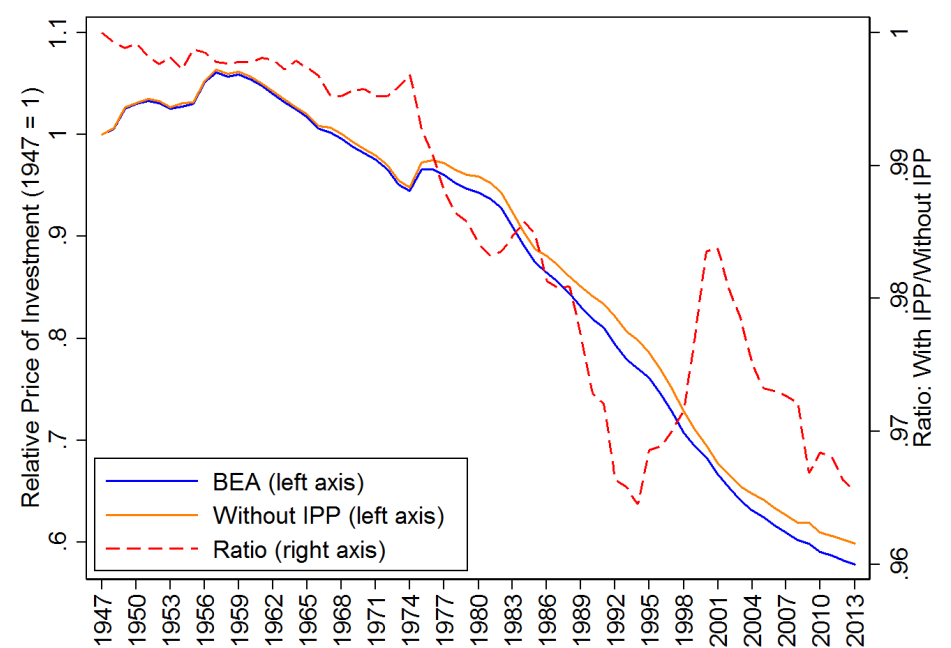

(c) Depreciation Rate With and Without IPP

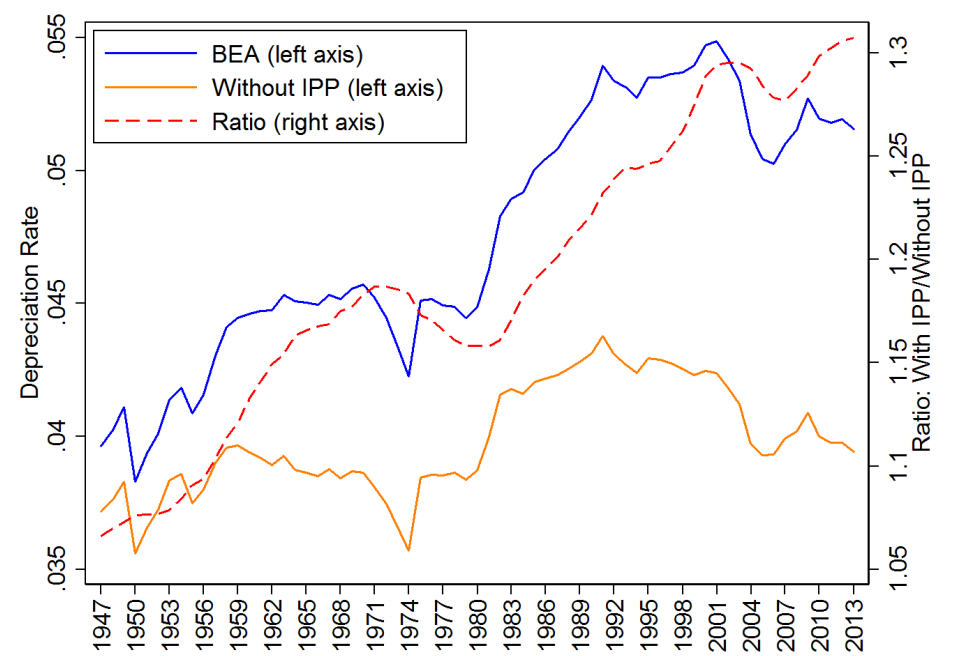

Notes: The construction of aggregate investment, investment price, and depreciation rate for, respectively, panel (a), (b) and (c), is discussed in detail in Section 3.2. 
Figure 6: Effects of IPP Capitalization on Labor Share, US 1947-2013

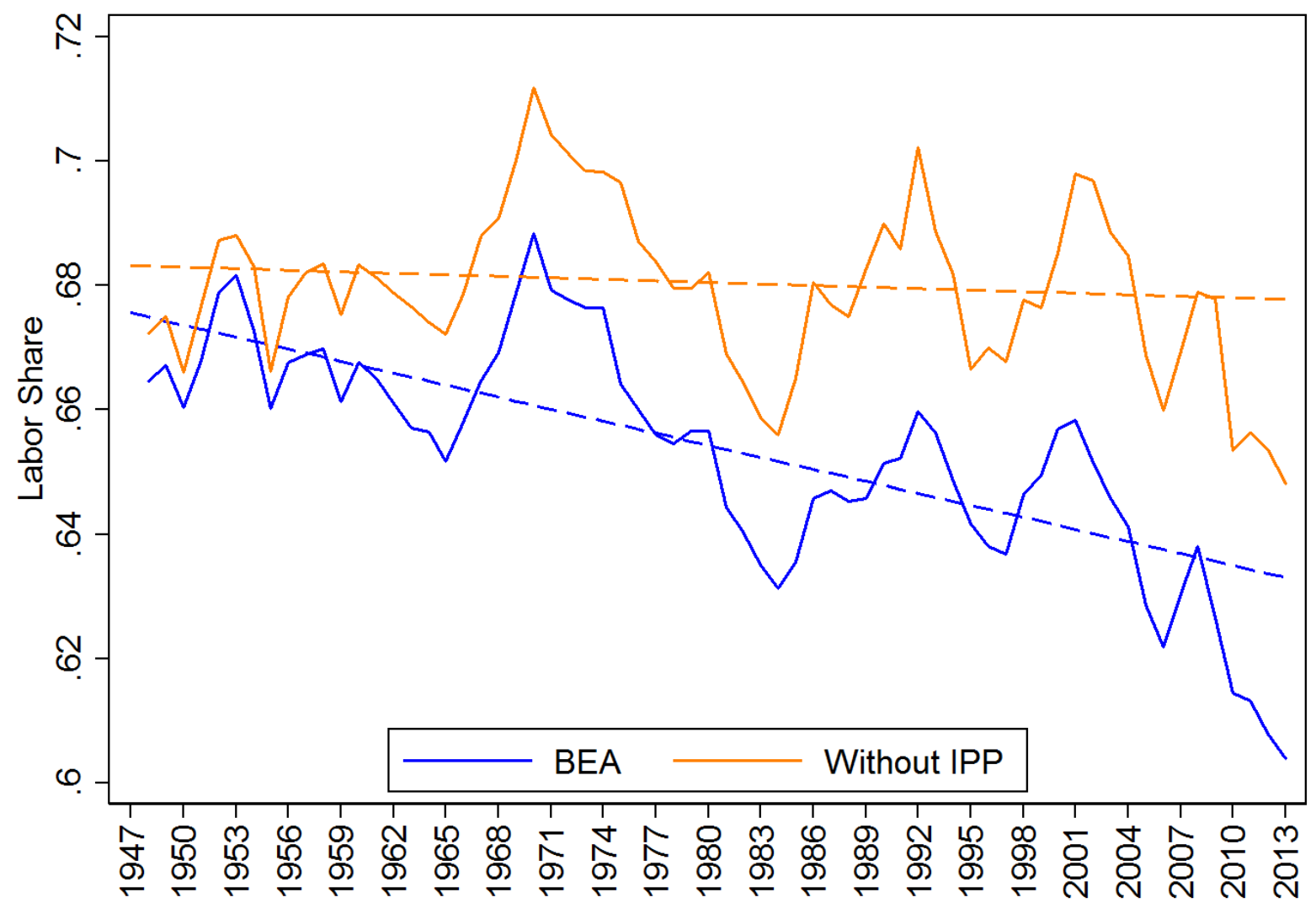

Notes: The labor share with IPP refers to the benchmark definition described in Section 2.1 and uses only post2013 BEA revision data (also depicted in Figure 1). The labor share without IPP refers to the counterfactual labor share that results from entirely removing IPP capitalization by setting $v, \delta$ and investment to their values without IPP in the computation of labor share, see Section 3. The underlying linear trend for labor share without IPP is not significantly different from zero from 1947 to 2012; the plotted dashed line refers to 1947-2010. 
Figure 7: A Decomposition of the Effects of IPP Capitalization on Labor Share: It is All in Capital Accumulation

(a) Depreciation, $\delta_{t} k_{t}^{x} / v_{t}$

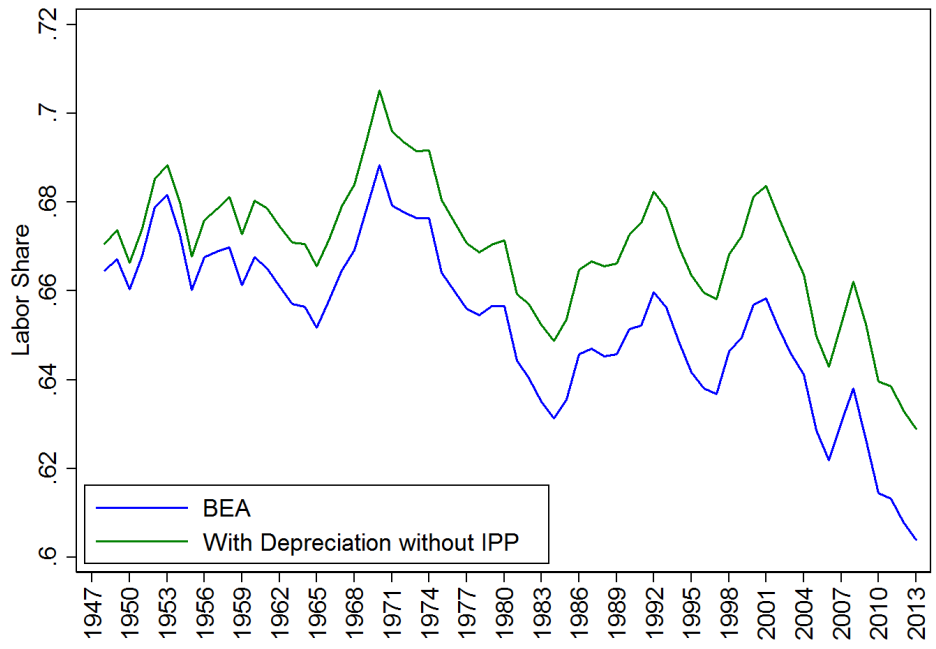

(c) Price of Investment Through $R_{t}$ \& Capital Accumulation

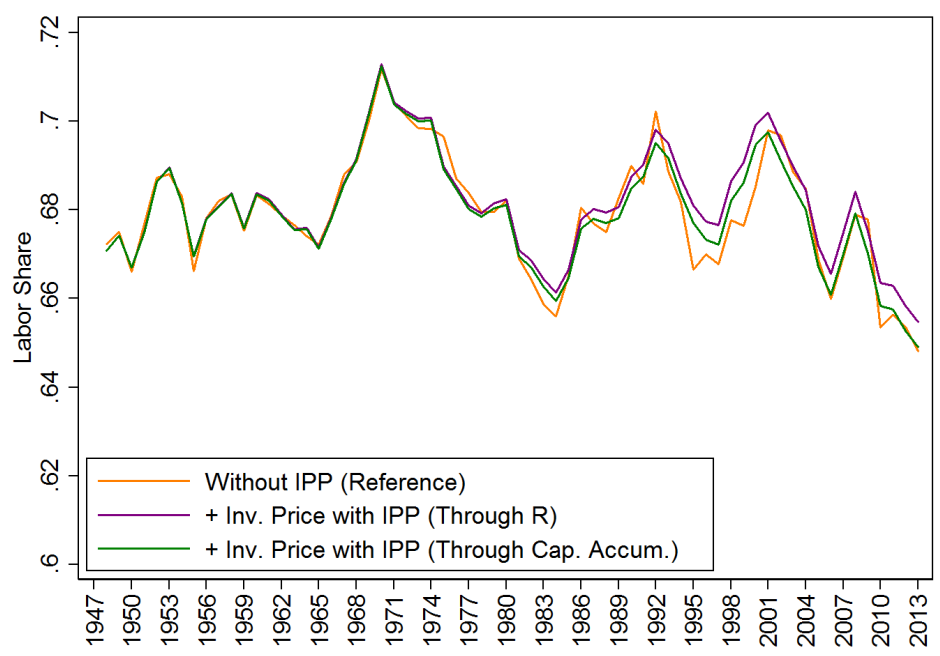

(b) Investment, Its Price and Depreciation Rate

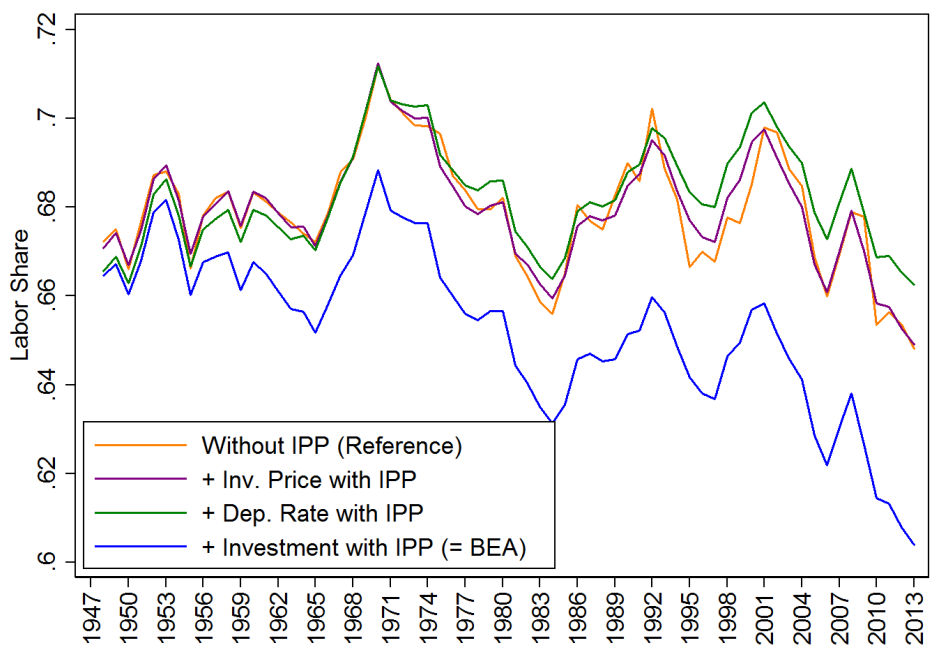

(d) Depreciation Rate Through $R_{t} \&$ Capital Accumulation

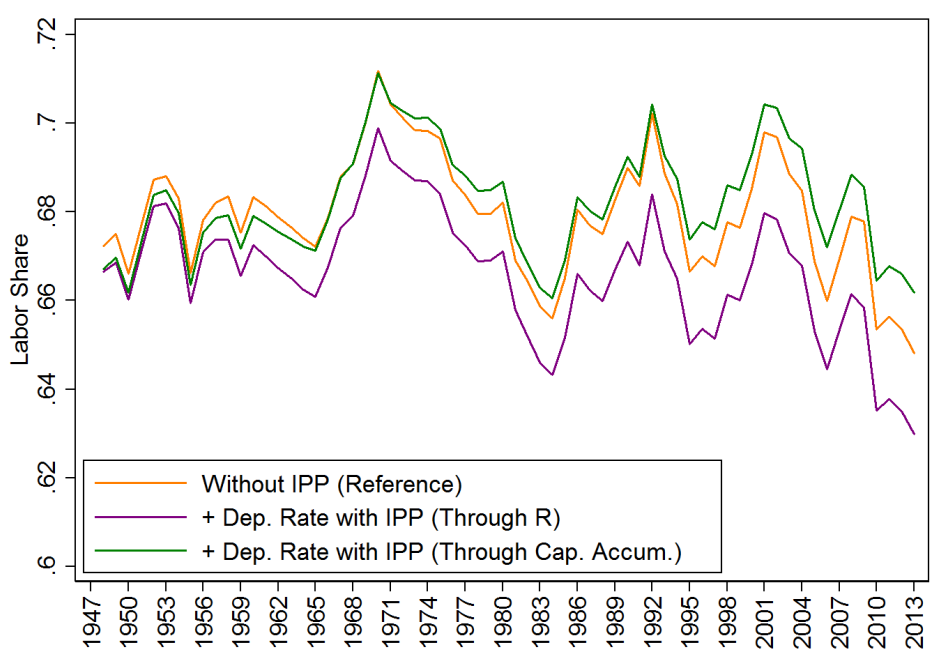

Notes: In panel (a) the reference scenario is the benchmark labor share with IPP and the counterfactual labor share results from imposing capital depreciation, $\delta_{t} k_{t}^{x} / v_{t}$, without IPP to the reference scenario. In panel (b) the reference scenario is benchmark labor share without IPP and the counterfactual experiment consists of sequentially adding to the reference scenario the investment price with IPP, the depreciation rate with IPP, and investment with IPP such that we end up recovering benchmark labor share with IPP. The last two panels take the benchmark labor share without IPP as reference scenario and compute the counterfactual labor shares that results from adding, respectively, the price of investment (in panel (c)) and depreciation rate (in panel (d)) with IPP to the reference scenario separately revealing their effects through $R_{t}$ and through capital accumulation. 
Figure 8: The Effects of IPP Capitalization on Aggregate Capital

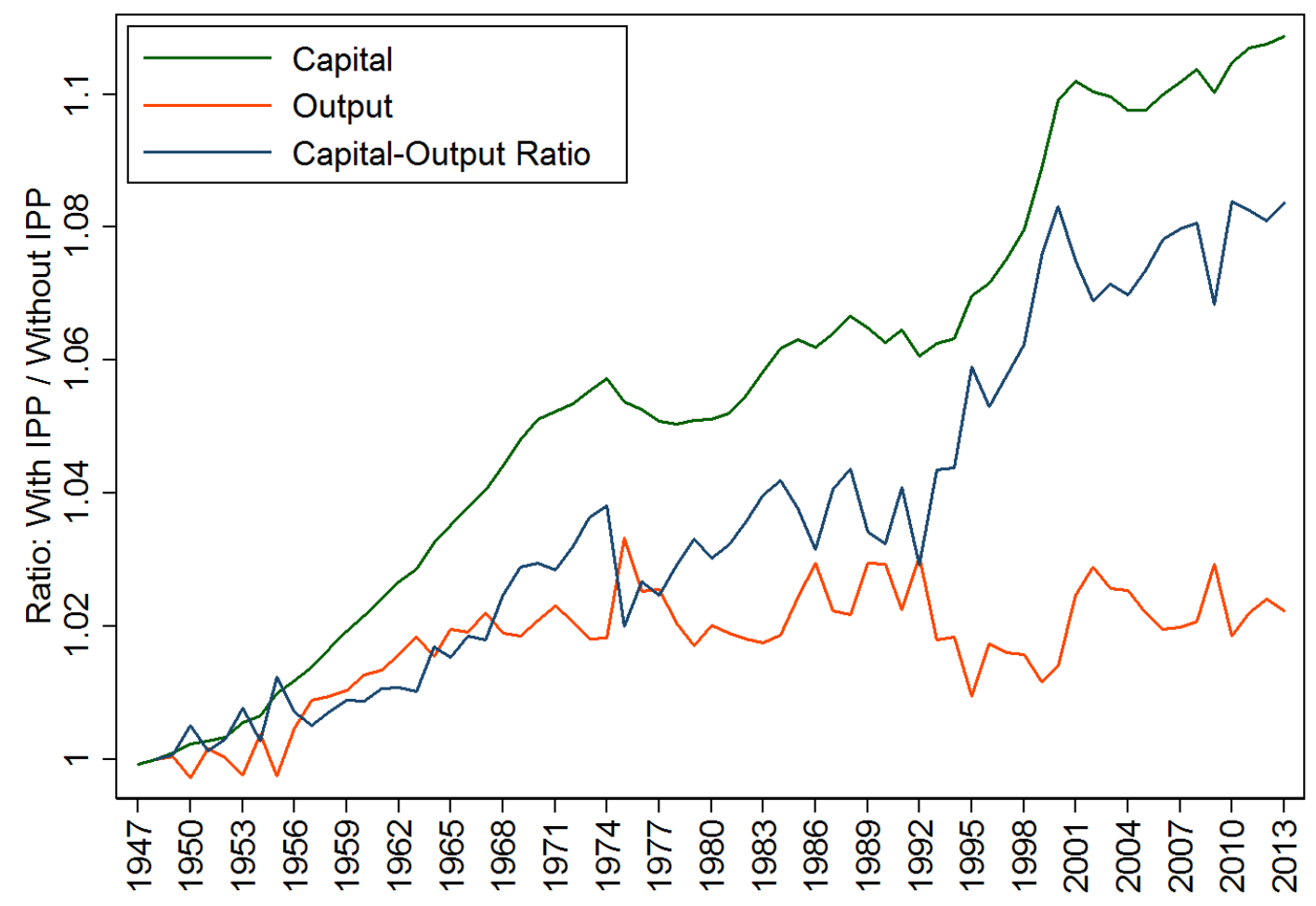

Notes: The effects of IPP capitalization on capital, output and the capital output-ratio refer to the ratio between each of these variables agumented with IPP and without IPP. 
Figure 9: Effects of Software, R\&D and Artistic Originals Capitalization on Labor Share

(a) Software, R\&D and Artistic Originals Investment Shares, BEA

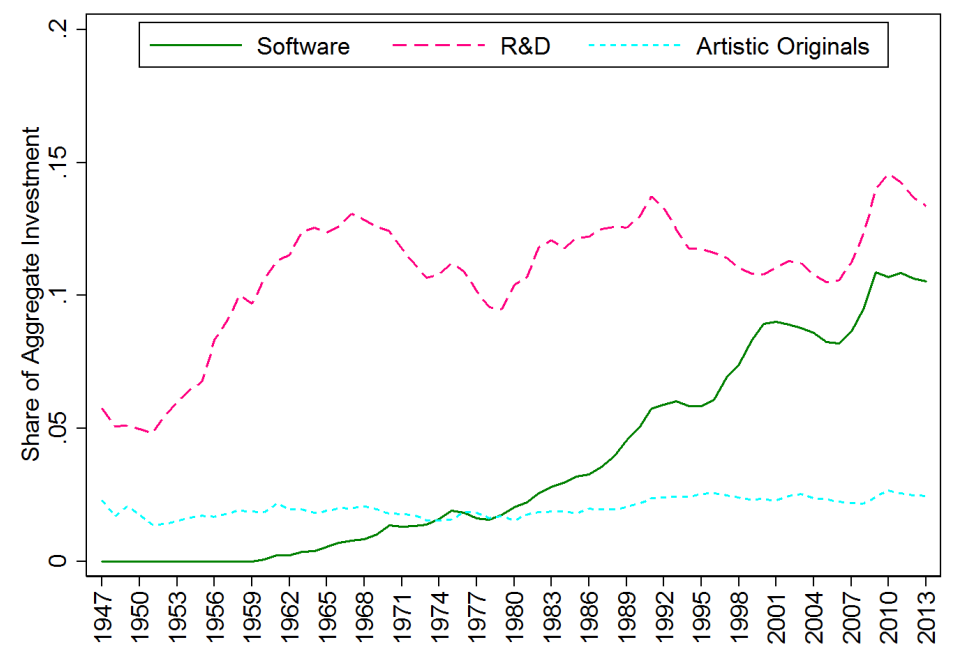

(b) Effects of IPP Capitalization on Labor Share: By Type of IPP

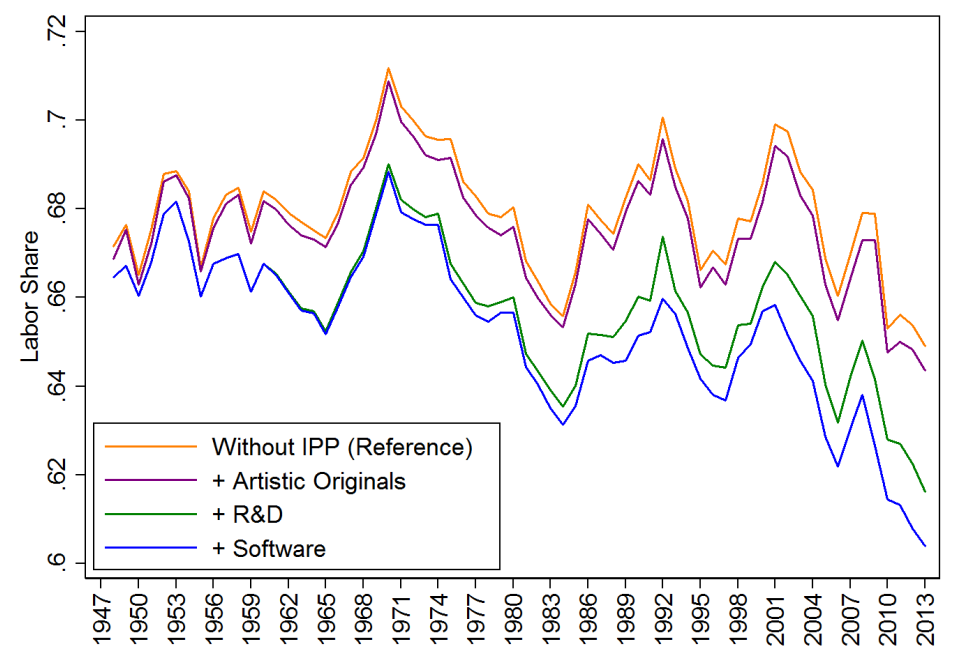

(c) Labor Share Decline Due to IPP Capitalization: By Type of IPP

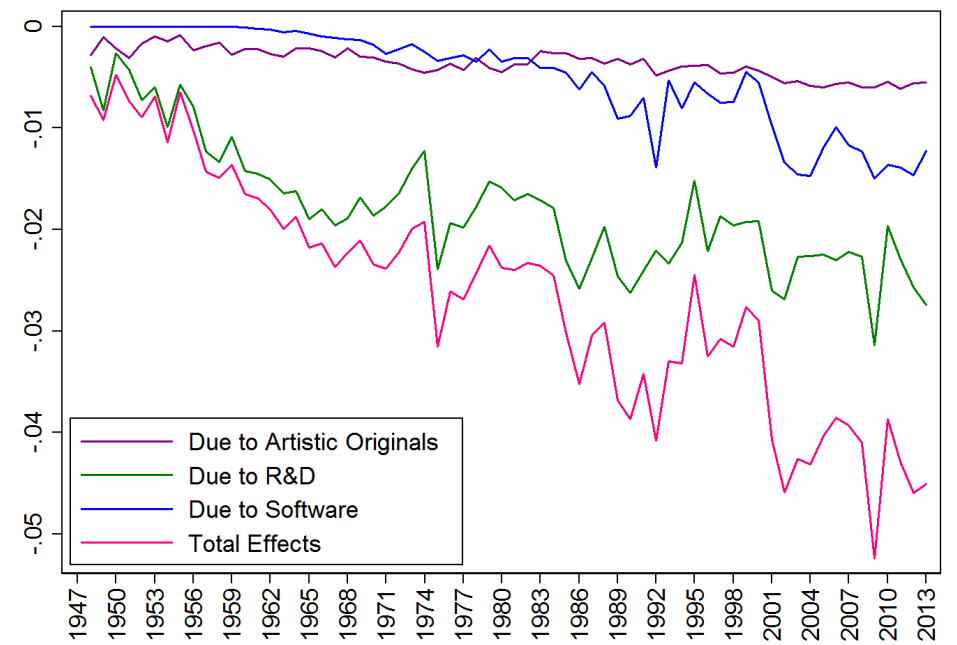

Notes: Panel (a) shows the IPP components shares of aggregate IPP investment. In panel (b) the reference scenario is benchmark labor share without IPP and the counterfactual labor share consists of sequentially adding artistic originals, R\&D and sofware capitalization. Panel (c) shows the amount of labor share decline separately generated by each type of IPP capital. 
Figure 10: Effects of Private and Government IPP Capitalization on Labor Share

(a) Structures, Equipment and IPP Investment Shares, BEA

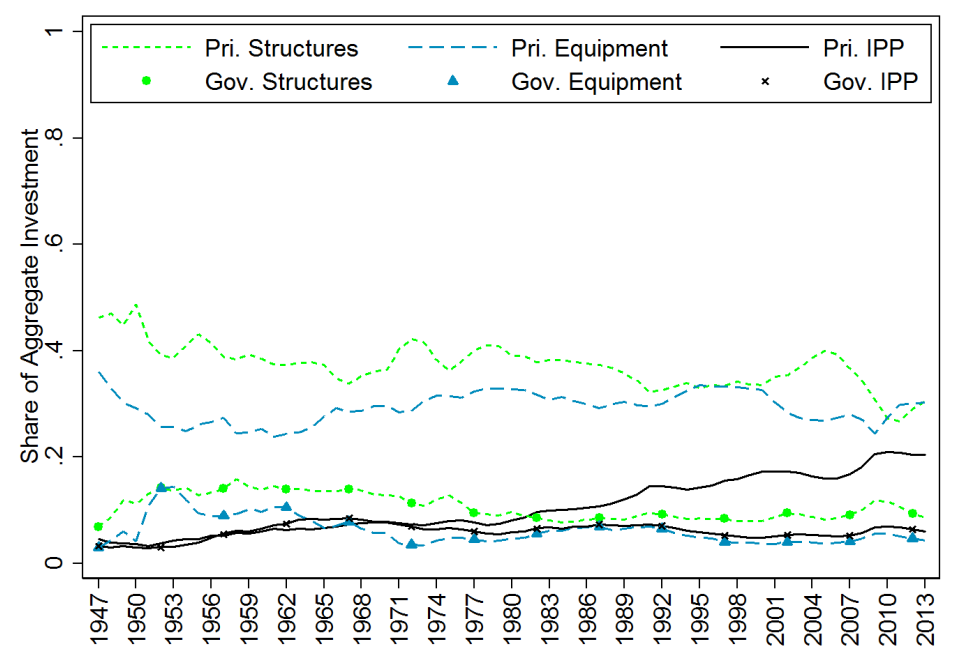

(b) Effects of Private and Government IPP Capitalization on LS

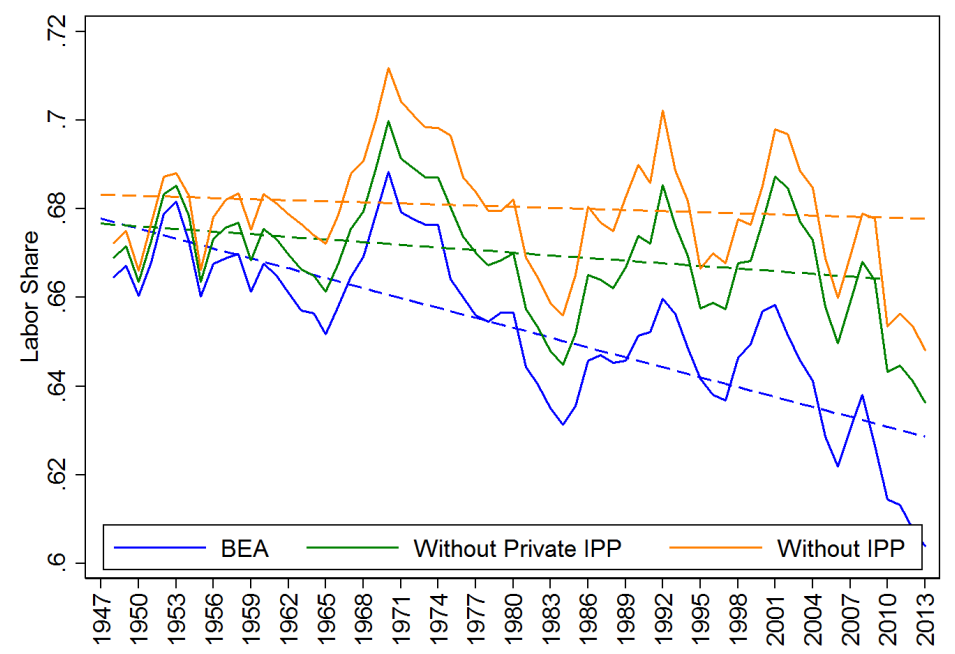

(c) Percentage of LS Decline Due to Private IPP Capitalization

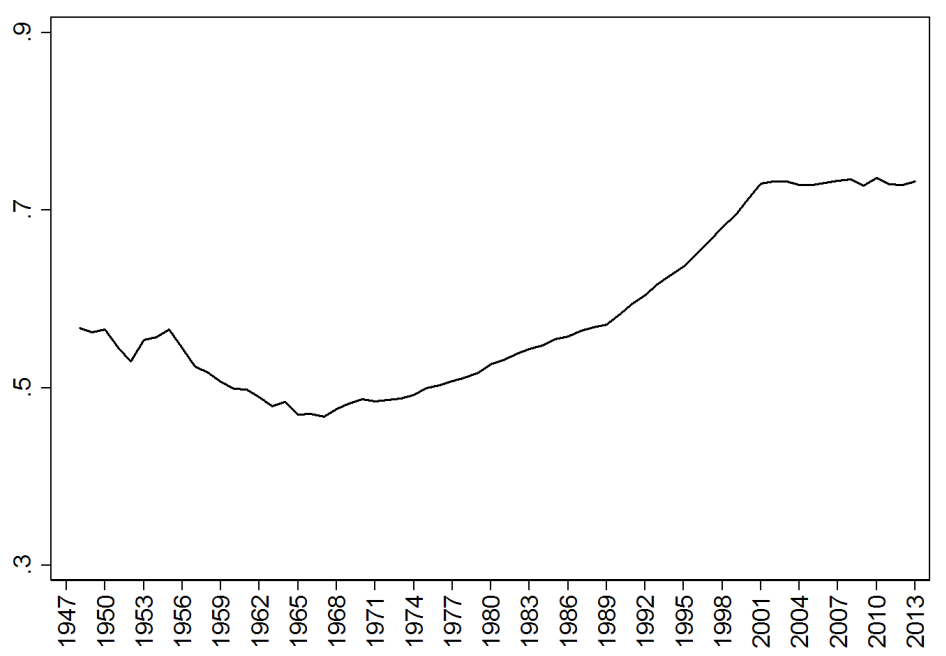

Notes: Panel (a) shows the evolution of each type (i.e., structures, equipment and IPP) of private and government investment as share of aggregate investment. Panel (b) shows the effect on the labor share from private and government IPP capitalization separately. The reference scenario is benchmark labor share with IPP capitalization. Panel (c) shows the reduction in labor share generated by the capitalizaiton of private IPP as a percentage of the total labor share decline. See section 3.5 for a discussion. 
Figure 11: Effects of IPP Capitalization on Corporate Labor Share

(a) Corporate Labor Share, BEA 1947-2013

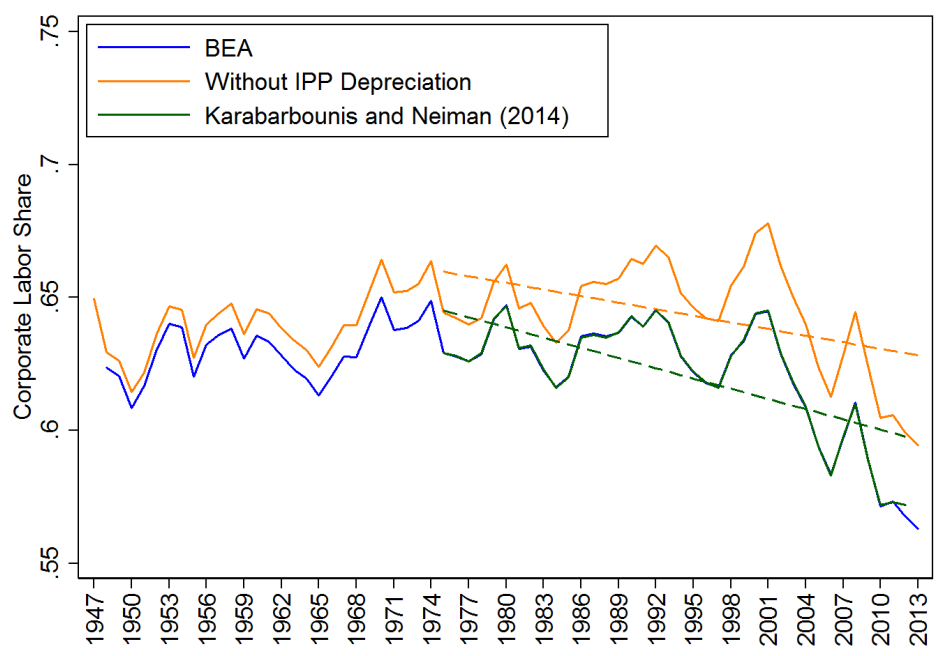

(c) Effects of IPP Capitalization on Corporate Labor Share

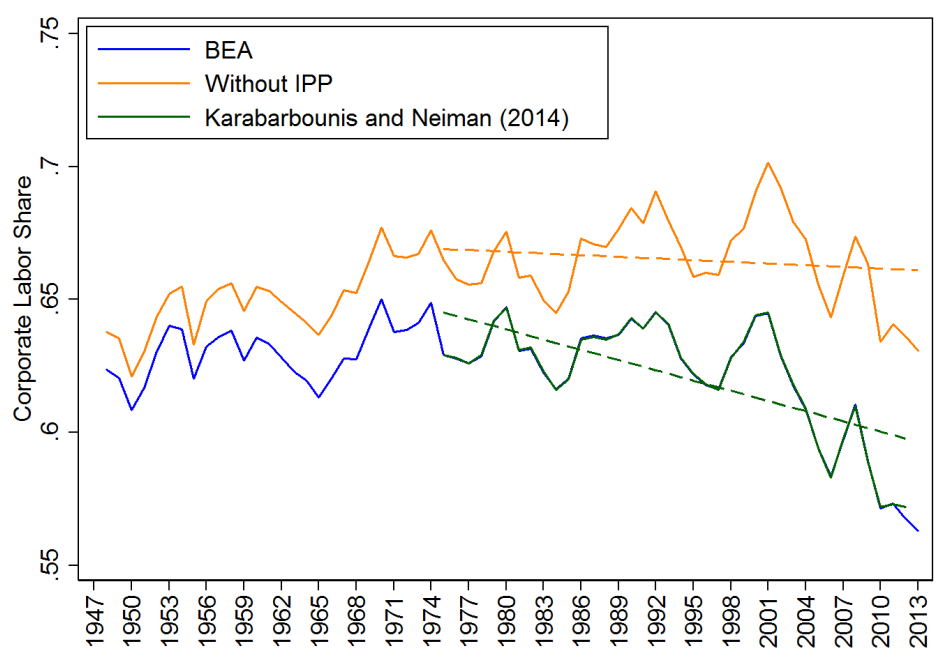

(b) Struct., Equip. and IPP Inv. Shares, Corporate Sector, BEA

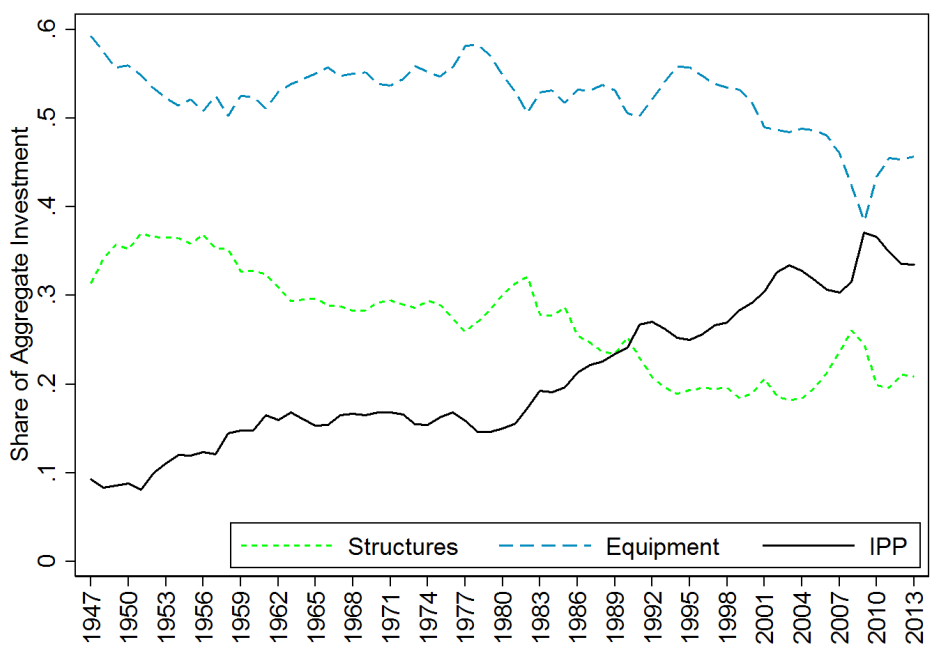

(d) Effects of IPP Capitalization, Decomposition

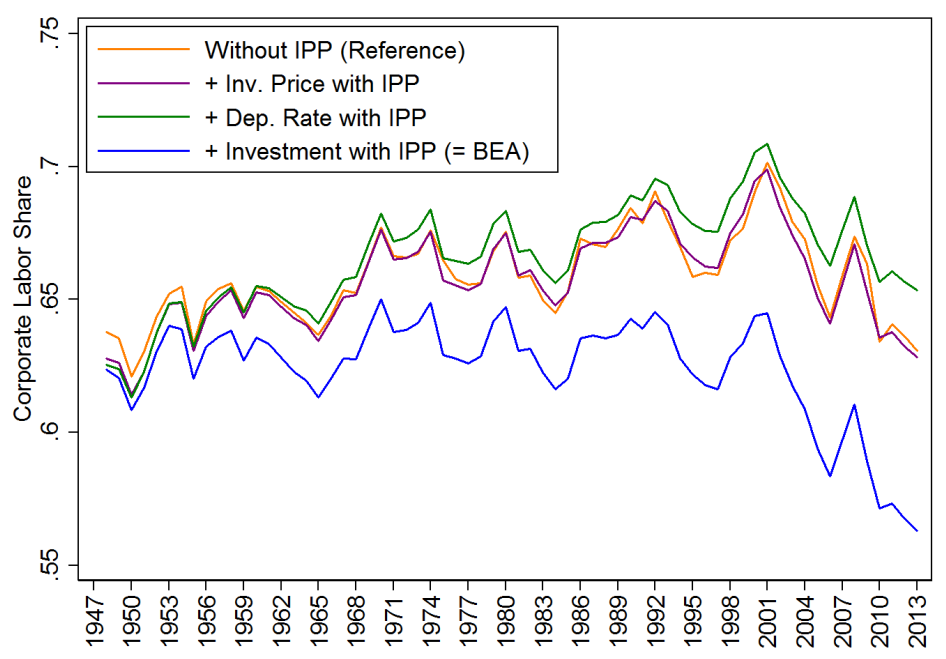

Notes: In panel (a) the reference scenario is the benchmark labor share for the corporate sector from the post-revision data (i.e. the blue line). This measure of labor share is identical to the updated labor share data supplied by Karabarbounis and Neiman for their 2014 QJE paper for the subperiod 1975 to 2012 (i.e. the green line). This panel shows the effects of removing IPP depreciation (i.e., the orange line). Panel (b) shows the share of nominal investment by type of assets. In panel (c), we remove the entire effect from IPP capitalization (i.e. the orange line). In panel (d), we decompose the effects of IPP capitalization by sequentially adding to the sans-IPP scenario, the effects from the price of IPP investment, the depreciation rate of IPP and the IPP investment. 
Figure 12: US Output Shares by Industry, BEA 1947-2013

(a) Growing Industries

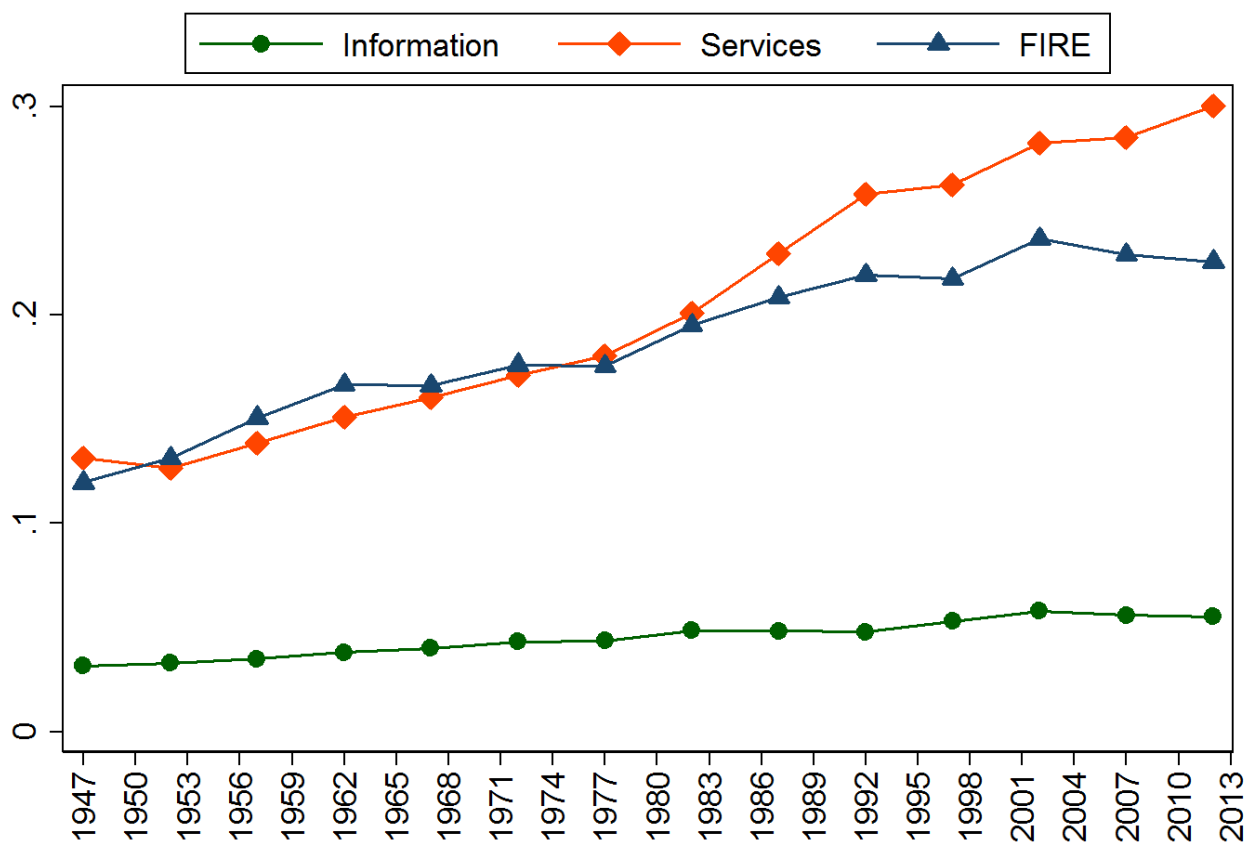

(b) Declining Industries

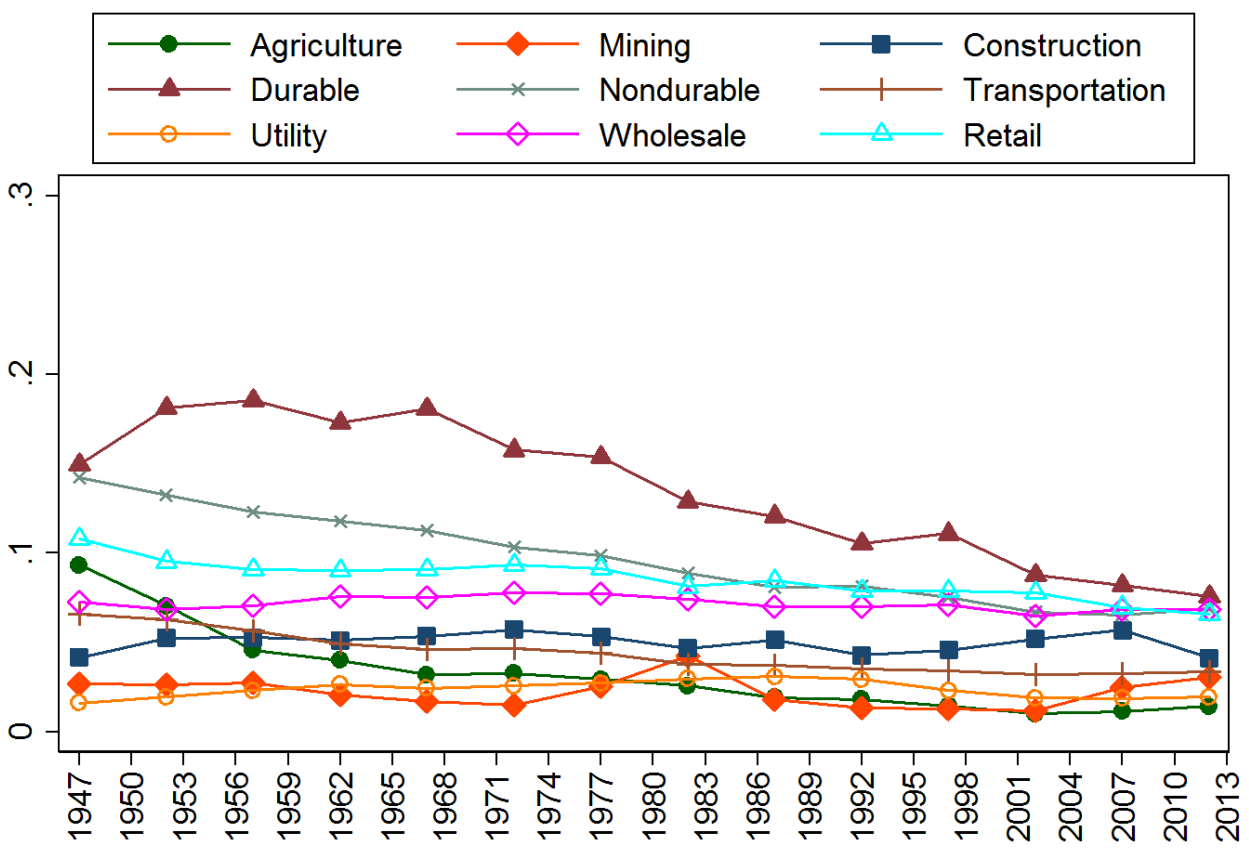

Notes: The output shares by industry are computed using NAICS classification as described in Section 4. 
Figure 13: Labor Share and IPP Capital Intensity by Industry: Pre- and Post-2000s

(a) Main Industries

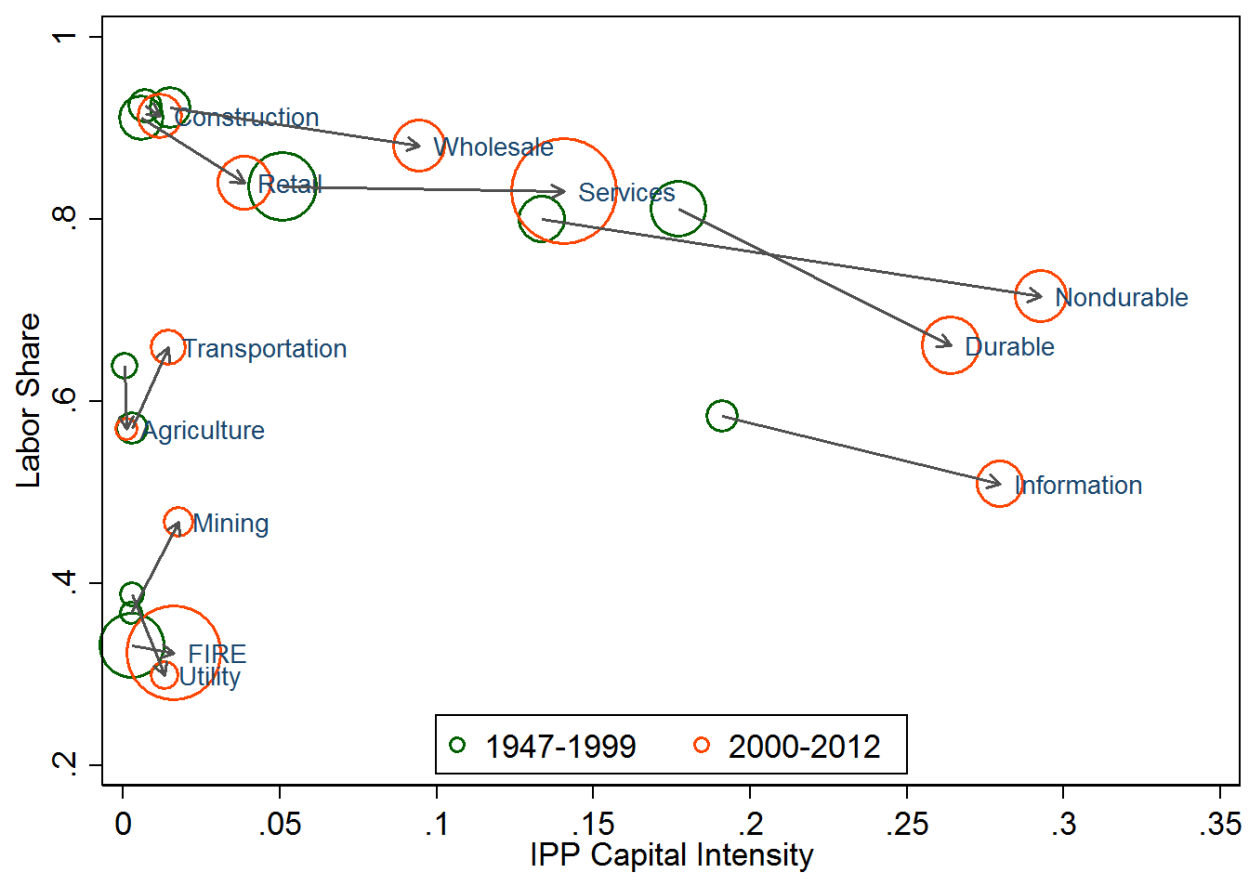

(b) Sub-Industries

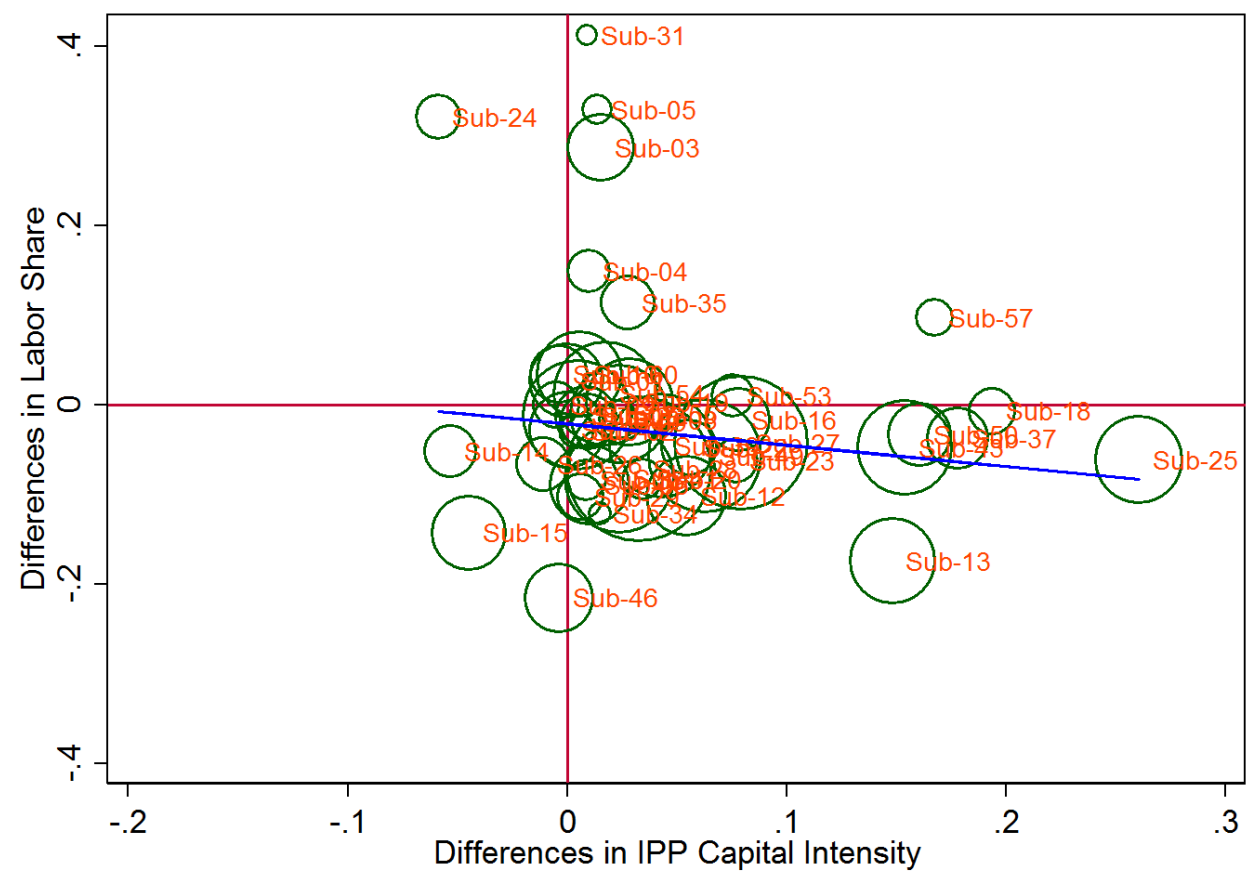

Notes: Labor share is computed by industry using NAICS classification, as described in Section 4. IPP capital intensity is the share of IPP capital in total capital by industry (or sub-industry). The size of the points refers to the industry-specific share of output in the aggregate economy. 
Figure 14: The Effects of IPP Capitalization on Labor Share By Industry

(a) Information

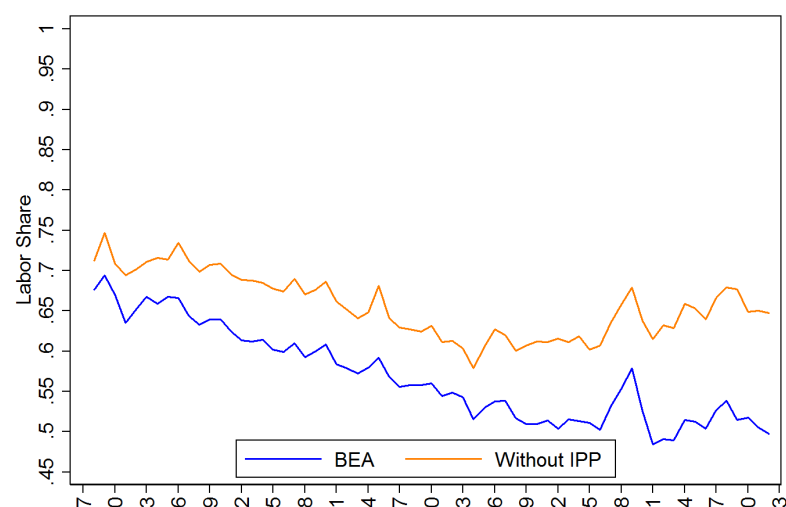

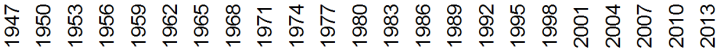

(c) Manufacturing: Nondurable goods

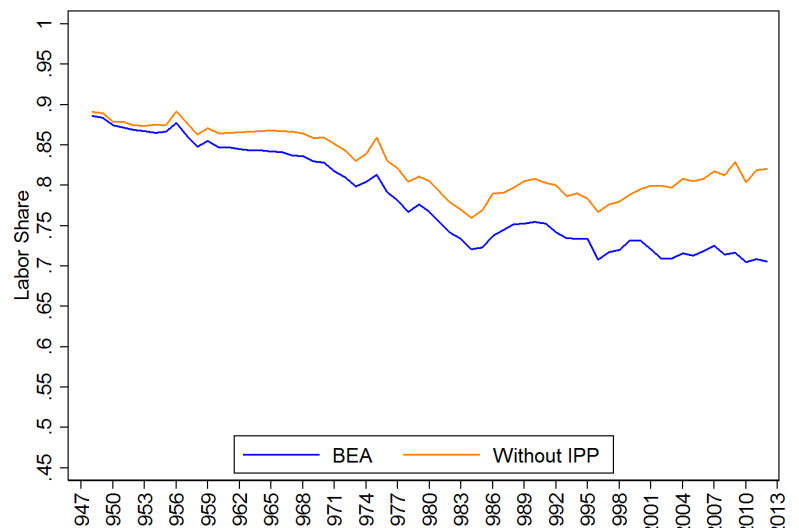

(e) Wholesale Trade

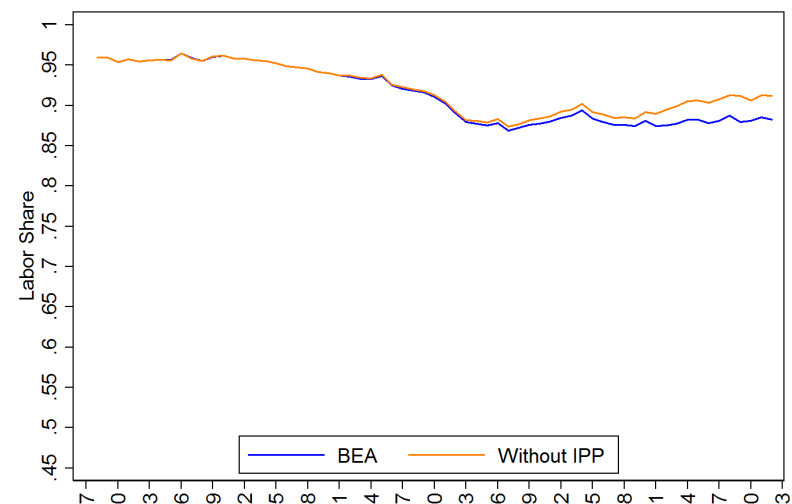

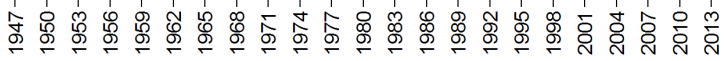

(b) Services

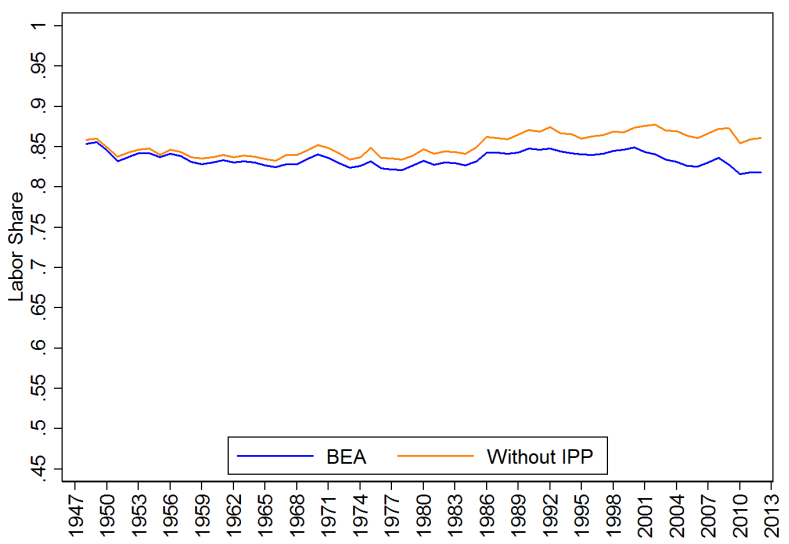

(d) Manufacturing: Durable goods

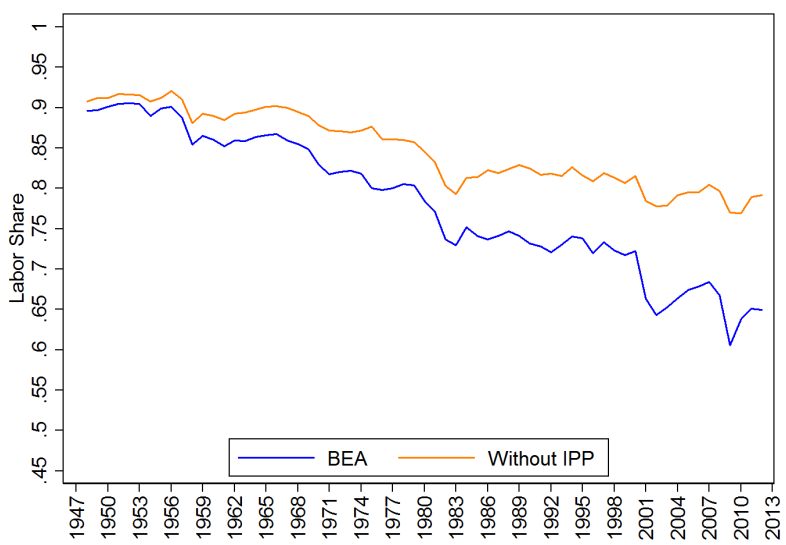

(f) Retail Trade

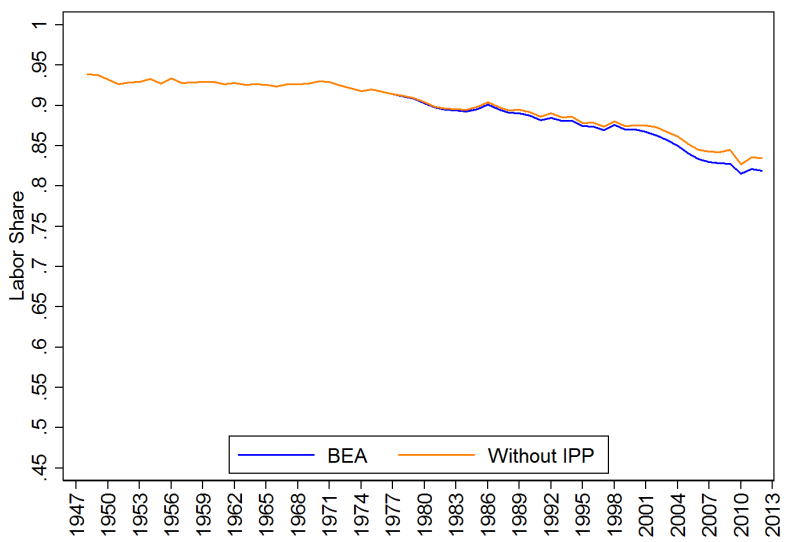

Notes: In each panel, the blue lines labeled "BEA" are the labor share constructed from the one-sector model for the six industries which invest appreciably in IPP capital. The orange lines labeled "Without IPP" are the counterfactual labor share constructed by removing the full effects of IPP capitalization on the price of investment, the investment flow and the depreciation rate. See Section 4 for a discussion. 